\title{
Estratégia em destaque: duas décadas de produção científica do evento 3 Es à luz da análise de redes sociais
}

\author{
Henrique César Melo Ribeiro ${ }^{I}$ \\ https://orcid.org/0000-0002-0704-1812 \\ I Universidade Federal do Delta do Parnaíba, PI, Brasil. \\ Doutor em Administração.
}

http://dx.doi.org/10.1590/1981-5344/25199

Este estudo investigou o perfil e as características da produção científica divulgada no Evento 3Es durante as Edições de 2003 a 2017.Utilizou-se as técnicas bibliométricas e, predominantemente, a sociométrica enfocando as redes de 1 e 2 modos, em 929 estudos identificados. Nas redes one-mode, constataram-se redes esparsas e alta centralidade de grau e de intermediação nas duas décadas investigadas. Na rede social das instituições, ficaram em evidência USP e FGV (SP). Tendo em consideração as redes de coautoria, à luz das centralidades de grau e de intermediação nas duas décadas de estudo no 3Es, destacaram-se os pesquisadores Carlos Ricardo Rossetto, Clóvis L. Machado-da-Silva e Manuel Portugal Ferreira. No que tange a rede two-mode que enfoca os autores e os temas em conjunto neste trabalho, vislumbram-se os temas com maior número de autores vinculados a estes, ou seja, estudiosos que buscaram publicar sobre estes assuntos durante as duas décadas do evento em investigação. As temáticas foram: visão baseada em recursos, formulação de estratégia, redes inter e organizacionais, desempenho organizacional, internacionalização, empreendedorismo e inovação. 
Palavras-chave: Congresso científico; Produção científica; Estratégia; Redes sociais one-mode; Redes sociais two-mode.

\section{Strategy in focus: two decades of scientific production of the $3 E$ s event in the light of social network analysis}

This study investigated the profile and features of the scientific production disclosed in Event $3 E s$ during the Editions from 2003 to 2017. Bibliometric techniques and predominantly sociometric techniques were used, focusing on networks of 1 and 2 modes, in 929 identified studies. In the one-mode networks, sparse networks and high degree and intermediation centrality were found in the two decades investigated. The institutions' social network highlighted USP and FGV (SP). With regard to coauthorship networks, in light of the centralities of degree and intermediation in the two decades of study at 3Es, the researchers Carlos Ricardo Rossetto, Clóvis L. Machado-da-Silva and Manuel Portugal Ferreira stood out. Regarding the two-mode network that focuses on the authors and themes together in this work, we glimpse the themes with the greatest number of authors linked to them, that is, scholars who sought to publish on these subjects during the two decades of the event research. The themes were: resource-based view, strategy formulation, inter and organizational networks, organizational performance, internationalization, entrepreneurship and innovation.

Keywords: Scientific Congress; Scientific production; Strategy; One-mode social networks; Two-mode social networks. 
Recebido em 07.09.2020 Aceito em 13.12.2021

\section{Introdução}

Os congressos científicos são vistos como meios de comunicação mais ágeis na transmissão, divulgação, troca, socialização e disseminação do conhecimento científico (ARBOIT; BUFREM, 2011; RIBEIRO; RIBEIRO, 2019), destacando assim um panorama da produção científica de uma determinada área do saber (LEITE FILHO, 2010), como no caso da Administração (BERTERO; CALDAS; WOOD JR., 1999; GALLON et al., 2008; CASSUNDÉ; BARBOSA; MENDONÇA, 2018).

Posto isto, realça-se o Encontro da Associação Nacional de PósGraduação e Pesquisa em Administração- ANPAD (Enanpad), que representa a maior base da produção científica na área de Administração, sendo considerado o evento científico mais importante do Brasil e o segundo maior do mundo (ANPAD, 2020), sendo que os pesquisadores costumam citar estudos relacionados ao citado evento ou aos periódicos oriundos da ANPAD na esperança de fomentarem as chances de aceitação de seus trabalhos (MACADAR; GRAEML, 2010; GUIMARÃES et al., 2018).

Além do Enanpad, existem oito eventos em áreas específicas com periodicidade trienal e ou bienal patrocinados pela ANPAD são eles: Encontro de Administração da Informação (EnADI), Encontro de Administração Pública e Governança (EnAPG), Encontro de Ensino e Pesquisa em Administração (EnEPQ), Encontro de Estudos em Estratégia (3Es),Encontro de Estudos Organizacionais (EnEO), Encontro de Gestão de Pessoas e Relações de Trabalho (EnGPR), Encontro de Marketing (EMA) e Simpósio de Gestão, Tecnologia e Inovação (Simpósio) (GUIMARÃES et al., 2018; RIBEIRO, 2020). Destaca-se o evento bienal (até o ano de 2017) 3Es (ROCHA et al., 2011) que enfoca e enquadra artigos com escopo da área de estratégia, passando pelo crivo do coordenador da divisão e dos referees (MARCON; BANDEIRA-DE-MELLO, 2016).

O referido evento já fora estudado, direta ou indiretamente, em alguns trabalhos científicos com foco na bibliometria e ou sociometria (SARAIVA; CARRIERI, 2009; ROSSONI et al., 2010; ROCHA et al., 2011; WALTER et al., 2010; WALTER; BACH; BARBOSA, 2012; WALTER et al., 2013; CUNHA; DEFINA; PASSADOR, 2014; SOARES et al., 2015; MARCON; BANDEIRA-DE-MELLO, 2016; VILELA; LOURENÇO; RESE, 2017; GUIMARÃES et al., 2018; TESTON; FILIPPIM, 2019), ratificando assim a envergadura e o relevo que o 3Es têm no âmbito estratégico no Brasil.

Entretanto, é preponderante salientar que o citado evento ainda não foi explorado de maneira única sob a ótica da bibliometria (NASCIMENTO et al., 2011) e tão pouco com destaque na Análise de Redes Sociais (ARS) enfatizando as redes one-mode e two-mode (TOMAÉL; MARTELETO, 2013; RIBEIRO; CORRÊA; RIBEIRO, 2019) nas duas décadas que o mencionado 
evento existe, ou seja, em suas oito edições que foram evidenciadas em biênios, iniciando-se em 2003, seguindo-se dos anos de 2005, 2007, 2009, 2011, 2013, 2015 e 2017.

Isto dito, contempla-se a questão de pesquisa que norteará este estudo: Qual o perfil e as características da produção científica divulgada no Evento 3Es durante as Edições de 2003 a 2017 à luz das redes sociais one-mode e two-mode? Versa-se assim o objetivo da pesquisa que é: investigar o perfil e as características da produção científica divulgada no Evento 3Es durante as Edições de 2003 a 2017 à luz das redes sociais one-mode e two-mode.

Enfatiza-se que a produção científica é um meio ímpar para o entendimento e a compreensão do conhecimento científico publicado, colocando em destaque e, consequentemente, reconhecendo os atores (pesquisadores e suas instituições de origem) envolvidos no processo de otimização do saber acadêmico junto a grupos de pesquisa e ao mesmo tempo à comunidade científica (RIBEIRO, 2019).

E a bibliometria, como área de pesquisa da Ciência da Informação, desempenha um papel acentuado na análise da produção científica de uma nação, uma vez que seus indicadores realçam o grau de aperfeiçoamento de uma área do conhecimento de um campo científico ou do saber (FERREIRA ARAÚJO; ALVARENGA, 2011), como é o caso da área de Administração (MEDEIROS ARAÚJO et al., 2014), e suas temáticas (RIBEIRO, 2020), que se conectam com o campo do conhecimento Ciência da Informação, por meio da grande área do saber das Ciências Sociais Aplicadas (Coordenação de Aperfeiçoamento de Pessoal de Nível Superior - CAPES, 2021).

Por conseguinte, enfatiza-se que o campo da Administração tem se voltado aos estudos bibliométricos e que tais revisões da literatura permanecem bastante pontuais (CASSUNDÉ; BARBOSA; MENDONÇA, 2018). Logo, a bibliometria é considerada uma técnica essencial para se investigar o acervo de estudos divulgados em meios de comunicação da área de administração, como periódicos (FAVARETTO; FRANCISCO, 2017; OLIVEIRA JUNIOR et al., 2018) e ou congressos científicos (BORBA; HOELTGEBAUM; SILVEIRA, 2011), ou em ambos (KNEIPP et al., 2011).

Sendo assim, o campo da bibliometria é essencial na ARS (MORAES; FURTADO; TOMAÉL, 2015), sendo primordial também como alicerce e norte para se chegar nas análises de redes one-mode e ou two-mode (RIBEIRO; CORRÊA; RIBEIRO, 2019), contribuindo assim para se avaliar o conhecimento científico e a mensuração do fluxo de informação, observa se, com isso, a inerência existente entre a bibliometria e as redes sociais (FRANCISCO, 2011).

Justifica-se a realização desta pesquisa, como foco no tema estratégia à luz do evento científico 3Es, em razão de a estratégia ser 
uma temática atual e de interesse sempre presente nas áreas do conhecimento da Ciência da Informação e da Administração, em especial (MIRANDA, 2018), trazendo assim contribuições acadêmicas em estado da arte para a literatura científica da área de Administração.

Fundamenta-se também a realização deste estudo por entender que este traz à tona e, em seu bojo, as nuances da área de estratégia retratada mediante a publicação de 929 artigos em duas décadas do evento 3Es que enfoca predominantemente pesquisas no contexto estratégico, contribuindo com isso para visualizar e entender como estão se comportando os estudos com este viés e, ao mesmo tempo, compreender as particularidades destas pesquisas, sob a óptica dos indicadores sociométricos one-mode e two-mode.

Enfocando as redes de 1 e 2 modos, justifica-se realizar este estudo pelo fato de o mesmo adentrar, predominantemente, nas técnicas de análise de redes sociais, one-mode e two-mode (TOMAÉL; MARTELETO, 2013), sendo que a análise de redes de dois modos manifestará neste estudo a conexão entre dois conjuntos de atores com atributos distintos (ALARCÃO; SACOMANO NETO, 2016; RIBEIRO; CORRÊA; RIBEIRO, 2019), ou seja, os autores e os temas.

Reiterando e fortalecendo o entendimento e a compreensão das redes two-mode, estas caracterizam-se por ser Matriz Bipartida (twomode) sendo utilizada quando se tem dois conjuntos de atores diferentes; e neste caso, cada ator se posiciona em um dos eixos da matriz de relacionamento (WASSERMAN; FAUST, 1994). De maneira geral, a característica dos dois conjuntos de atores até pode ser a mesma, porém, os papéis enfocados por esses são distintos (MACHADO JUNIOR et al., 2016).

Outra justificativa de se adentrar nesta pesquisa é que, ao mesmo tempo que esta manifesta o estado da arte das pesquisas do âmbito da estratégia à luz de um evento científico consolidado da ANPAD, este trabalho científico é o primeiro a explorar e investigar todos os artigos divulgados no 3Es de 2003 a 2017, enfatizando com isso duas décadas de produção científica do campo do saber da Administração, em especial da área de estratégia, emergindo os indicadores de redes sociais, mostrando com isso a horizontalidade, interdisciplinaridade e multidisciplinaridade que o conhecimento científico das temáticas de estratégia contempla no panorama acadêmico nacional e, por que não dizer, internacional.

Em relação a tudo que foi dito até aqui, no que concerne a importância da realização deste estudo, suas justificativas e contribuições para a literatura científica nacional e, quiçá internacional, observa-se assim um gap de estudos com este foco e enfoque, reiterando e reforçando com isso sua preponderância e envergadura para a difusão, disseminação e socialização do conhecimento sobre estratégia em seu 
estado da arte, à luz do 3Es, que é um dos principais eventos da área no Brasil (MARCON; BANDEIRA-DE-MELLO, 2016).

Com isso, o citado estudo, além de dirimir possíveis gaps de estudos análogos a este, poderá também influenciar na construção de uma agenda de pesquisas similares a este em outros panoramas, no que corresponde ao âmbito internacional, contribuindo com isso para robustecer e alargar o saber da área de estratégia sob a óptica de eventos internacionais, proporcionando análises de estudos comparativos, replicar os conhecimentos e engrandecer e legitimar não somente o campo da estratégia, mas, também, a área do saber Administração.

\section{Fundamentação teórica}

Esta seção abordará os assuntos produção científica em estratégia e as redes sociais.

\subsection{Produção científica em estratégia}

A estratégia conecta-se com operações militares, em especial no que tange a condução de uma guerra ou na organização da defesa de uma nação. Dito isso, evidencia-se que houve uma adaptação, na segunda metade do século XX, da estratégia em seu foco original para o seu uso na área do saber Administração nos Estados Unidos. Tal adequação ocorreu em decorrência de que as organizações necessitavam planejar suas ações e operações para sobrevivência e continuidade de seus negócios (GONÇALES FILHO; CAMPOS; ASSUMPÇÃO, 2016). Entende-se, assim, a estratégia como sendo o processo assumido pelos atores localizados no topo da organização alicerçada e norteada por distintos padrões de ação (BIGNETTI; PAIVA, 2002).

Os conceitos da estratégia são inerentes a área de administração, tendo peso influenciador e colaborador para o aperfeiçoamento das funções que compõem as organizações, desde sua formulação até o seu posicionamento e diversificação no ambiente organizacional, sendo que tal panorama é retratado de forma ampla no meio acadêmico (CAMARGOS; DIAS, 2003).

Schneider, Carneiro, Serra e Ferreira (2009) afirmam que nas últimas décadas, pesquisadores vem teorizando e publicando estudos sobre estratégia sob a óptica das técnicas bibliométricas e ou sociométricas. Deste modo, segue alguns estudos publicados que vislumbraram a produção acadêmica nacional e ou internacional de estratégia como tema principal e ou em conjunto pegando como base artigos divulgados em congressos e ou em periódicos científicos.

Bertero, Vasconcelos e Binder (2003) apresentaram um levantamento sistemático e uma avaliação crítica da produção científica em Estratégia Empresarial no Brasil. Os achados mostraram uma 
proeminência de estudos divulgados em colaboração. Os autores mais produtivos foram: Silva, Jorge F., Contador, José C., Moraes, Walter, Machado-da-Silva, Clóvis. As instituições mais profícuas foram: USP, UFPR, UFRGS, PUC (RJ), FGV (SP), UFMG, UFPE. Os temas mais abordados foram: fundamentos organizacionais, planejamento estratégico, processo decisório, recursos e competências, alianças e redes estratégicas, competitividade.

Schneider et al. (2009) analisaram a influência de Porter nos trabalhos brasileiros em estratégia, a partir dos trabalhos selecionados e apresentados no EnANPAD. Os resultados evidenciam a predominância de artigos publicados em parceria; que os autores mais profícuos foram: Jorge Ferreira da Silva, Jorge Manoel Teixeira Carneiro. E as instituições com maior produção foram: PUC (RJ), UFMG, UPM, UFPE, PUC (SP), UNIVALI.

Rossoni et al (2010) analisaram as publicações entre 2001 e 2006, nos anais dos EnAnpad e 3Es, objetivando avaliar quantitativamente os delineamentos de pesquisa utilizados e analisar tendências acerca dos padrões de estratificação e cooperação na área de estratégia. Os autores verificaram que, ao longo do período investigado, houve crescimento da área de estratégia no que está relacionado ao número de artigos, autores e instituições, com ocorrência de maior cooperação na produção acadêmica.

Walter et al. (2010) analisaram a cooperação entre pesquisadores de diferentes instituições, a internacionalização dessas cooperações e a rotatividade de autores na produção científica na área de estratégia no Brasil. Os autores constataram que as IESs com maior destaque foram: USP, FGV (SP), UFRGS, UFMG, UFSC e PUC (PR). E que os autores mais profícuos e com maior número de laços foram: Jorge Ferreira da Silva e Clóvis L. Machado-da-Silva.

Ribeiro, Muritiba e Muritiba (2012) investigaram o perfil das pesquisas e o crescimento dos temas "governança corporativa" e "estratégia" em conjunto nos artigos publicados nas Revistas Qualis B2 a A1, no período de 2000 a 2010. Os autores que se destacaram foram: Richard Saito e Wesley Mendes-da-Silva; as instituições com maior produção foram: FGV (SP), FGV (RJ), USP e PUC (SP).

Watanabe, Gomes e Hoffmann (2013) identificaram como ocorre a cooperação entre grupos de pesquisa em estratégia no Brasil. Os autores observaram a existência de redes esparsas, com predomínio de relações fracas e estrutura do tipo centro-periferia. Os grupos mais centrais são os que mais se envolvem com instituições internacionais, influenciando à posição de centralidade dos atores. Os grupos centrais também são os que mais publicam, sugerindo que a conectividade tende a potencializar a produção científica em estratégia. 
Bueno, Rocha, Silva e Cruz (2014) analisaram as publicações da Revista Brasileira de Estratégia no período de 2008 a 2012. Os autores observaram a baixa densidade nas redes de coautoria, observando assim fragilidade na cooperação entre os pesquisadores da área. Conclui-se a necessidade de se manter mapeada o perfil e as características das publicações do campo da estratégia.

Matos, Venâncio e Dutra (2014) analisaram a produção científica sobre a gestão estratégica em Instituições de Ensino Superior publicada nos anais dos eventos acadêmicos da Associação Nacional de PósGraduação em Administração (ANPAD) e na base de dados Scientific Electronic Library Online (SciELO) no período de 1997 a 2012. Os principais achados mostraram que o autor mais prolífero era Leonardo Rocha de Oliveira; as instituições mais profícuas foram: PUC (RS), PUC (PR), UFPR.

Ribeiro, Costa e Ferreira (2014) mapearam o perfil e a evolução da pesquisa em Governança Corporativa e Estratégia, no período 1990 a 2012, nos periódicos internacionais da área de Administração. Os resultados permitem concluir que houve um crescimento dos trabalhos a partir de 2002, que Wright e Filatotchev são os autores mais produtivos. As instituições que ficaram em destaque foram: Harvard University, University of Nottingham, City University London, University of Texas e University of Michigan. Observou-se também baixa densidade das redes sociais dos atores.

Ferreira et al. (2015) descreveram a evolução dos estudos sobre estratégia no setor público. Os resultados evidenciam que os temas mais difundidos foram: planejamento estratégico, responsabilidade socioambiental, recursos e competências, Balances Scorecard, estratégia de posicionamento, processo decisório, mudanças estratégicas.

Andrade, Paiva, Alcântara e Brito (2016) analisaram a produção acadêmica sobre estratégia como prática (strategy as practice), buscando compreender o perfil e as tendências do campo a partir do texto seminal de Whittington, R., Strategy as Practice. O artigo revela que os autores mais profícuos com também os mais citados foram: Jarzabkowski, P., Whittington, R. No que está relativo as redes de coautoria, os pesquisadores observaram uma forte centralidade de alguns estudiosos, tais como Paula Jarzabkowski e Richard Whittington, bem como os países com maior produtividade (Inglaterra, Canadá, Austrália).

Marcon e Bandeira-de-Mello (2016) analisaram nove anos (20032011) da pesquisa em estratégia no Brasil publicada nos principais periódicos de administração do país, e nos anais do EnANPAD, na divisão de Estratégia em Organizações (ESO), e do 3Es. Os principais resultados indicaram a tendência de crescimento da pesquisa nos temas sobre 
negócios internacionais e sobre sustentabilidade socioambiental e ética corporativa.

Ribeiro e Corrêa (2018) investigaram a representatividade e as particularidades da produção acadêmica divulgada pela Revista IberoAmericana de Estratégia durante o período de 2002 a 2015. Os autores observaram que a rede social das IESs se apresenta dispersa e com baixa interação, impactando em uma alta centralidade de grau e de intermediação, que é refletida por meio das instituições: UNINOVE, USP e FGV (SP). Dos 93 temas identificados neste artigo, oito aparecem como os mais publicados: internacionalização, estratégias, sustentabilidade, empreendedorismo, inovação, balanced scorecard, gestão ambiental e responsabilidade social.

Os estudos manifestados nesta seção contemplam de maneira ampla as especificidades da produção acadêmica da área de estratégia no âmbito nacional e internacional, à luz de eventos e ou periódicos científicos, trazendo ao foco informações e conhecimentos importantes e necessários para o melhor entendimento no tocante a estratégia no meio acadêmico.

Contudo, nenhum destes trabalhos vislumbrados neste tópico traz em seu bojo, de maneira mais predominante, a produção científica integral do evento científico 3Es em suas duas décadas de vida, que, neste caso, esta pesquisa enfoca contribuindo assim para melhor compreensão da diversidade das redes de colaboração one-mode e twomode para evidenciar em uma ótica diferente a performance e as particularidades da produção acadêmica de estratégia à luz do referido evento ora investigado.

De maneira geral, no tocante da produção científica em estratégia no Brasil, os estudos divulgados nesta seção, aferem características e interessantes resultados sobre o comportamento e as características da estratégia em diferentes enfoques quanto a comunicação do conhecimento científico e sua difusão, disseminação e socialização.

De certa maneira, tais estudos traduzem, em seu determinado período, os quais foram publicados, o estado da arte da estratégia, trazendo, como dito anteriormente, suas respectivas especificidades metodológicas e de indicadores bibliométricos e ou sociométricos que ajudam aos pesquisadores, estudantes e ou leitores a entender e compreender as nuances enriquecedoras que a área de estratégia proporciona para aglutinar, robustecer e alargar a importância que a Administração, como campo do saber, tem para a criação de valor científico para a academia. 


\subsection{Redes sociais (sociometria)}

O campo científico é um sistema social, e este, pode ser traduzido por meio das redes sociais (MACHADO-DA-SILVA; ROSSONI, 2007). A análise de redes sociais é essencialmente interdisciplinar, visto que suas contribuições são vislumbradas em diferentes áreas do saber, como as ciências da informação, administração, contabilidade, finanças, dentre outras (PARREIRAS et al., 2006; ROSSONI; HOCAYEN-DA-SILVA; FERREIRA JÚNIOR, 2008;NASCIMENTO; BEUREN, 2011; MENDES-DASILVA; ONUSIC; GIGLIO， 2013; FAVARETTO; FRANCISCO， 2017; RIBEIRO; RIBEIRO, 2019).

Existem uma série de conceitos-chave primordiais para 0 entendimento, a compreensão e discussão da análise de redes sociais, que são: a) ator - objeto de pesquisa na análise de redes sociais; b) laço relacional -conexão constituída entre um par de atores; c) díade relacionamento constituído entre dois atores (rede mais simples); d) tríade - possíveis laços de conexão existentes entre um conjunto de três atores; e) subgrupo - conjunto de atores e todos as ligações entre os mesmos; f) grupo - conjunto finito de atores; g) relação -ajuntamento de conexões de um tipo característico entre membros de um grupo; e h) rede social - conjunto finito de atores e suas respectivas relações (WASSERMAN; FAUST, 1994; MATHEUS; SILVA, 2006; ROSSONI; HOCAYEN-DA-SILVA; FERREIRA JÚNIOR, 2008; NASCIMENTO; BEUREN, 2011; RIBEIRO; CORRÊA, 2013; SCARPIN et al., 2018).

Para Ribeiro (2015), as redes sociais retratam um conjunto de atores que se interligam, sendo que tais interações podem ser formais, informais, fortes ou fracas (GUIMARÃES et al., 2009). Posto isto, ressalvase a densidade que é uma das características principais das redes, pois é mensurada como extensão do número de conexões existentes numa determinada rede, em comparação com o número de ligações totais possíveis. Dito isto, a densidade manifesta a extensão na qual a rede social está interconectada (PAULI et al., 2019). É importante ressaltar que a análise da discussão dos resultados desta pesquisa, enfocou-se pela análise de propriedades estruturais a partir de medidas de centralidade e densidade.

Ainda cabe mencionar as estruturas de redes sociais small worlds, que ocorrem quando atores de uma rede de colaboração esparsa se mostram altamente agrupados, ou seja, com clusters bem definidos, mas, ao mesmo tempo, estão interagindo com atores de fora deste cluster bem definido, por intermédio de um pequeno número de atores. Geralmente, as propriedades de small worlds remetem a elementos das estruturas de relacionamento, tal como de instituições, fato preponderante para entender a mútua conexão entre estruturas locais e globais (ROSSONI; 
GUARIDO FILHO, 2007), ou seja, centralidade de grau e de intermediação respectivamente.

Posto isto, enfatiza-se que a centralidade é uma das propriedades de redes mais utilizada, a qual enfatiza as características relacionadas à relevância ou visibilidade de um ator em uma rede. Dentre os tipos de centralidades, realçam-se: (i) centralidade de grau - degree (evidencia a atividade relacional de um ator, ao mensurar o número de conexões de cada um destes em um grafo) e (ii) centralidade de intermediação betweenness (manifesta o potencial de intermediação dos atores, ao calcular quanto um determinado ator atua como norte contribuindo para alargar as ligações dos diversos atores da rede) (CRUZ et al., 2011; MORAES; FURTADO; TOMAÉL, 2015). Estas duas propriedades de centralidade foram usadas para a realização deste trabalho.

Isto posto, a análise de redes sociais pode ser: one-mode( 1 modo)e ou two-mode( 2 modos). A rede de um modo se caracteriza quando membros de uma rede social têm conexões com outros membros da mesma divisão, como,por exemplo: uma rede social composta apenas por pesquisadores. $\mathrm{E}$ a rede de dois modos se caracteriza quando seus atores possuem interações com membros de outras categorias, como, por exemplo: pesquisadores e suas respectivas instituições de origem (TOMAÉL; MARTELETO, 2013).

Diante disso, ressalva-se que as aplicações mais comuns das redes sociais se cultivam em pesquisas de um modo (one-mode), em outras palavras, os estudos na literatura majoritariamente pesquisam redes de um modo. Dito isto, no Brasil, é infrequente descobrir trabalhos que investigam redes de dois modos. Ou seja, os estudos de redes sociais de um modo suplantam muito, em quantidade, os estudos de redes sociais de dois modos em âmbito internacional. Em suma, na literatura científica, o número de estudos científicos divulgados sobre redes sociais de dois modos é cerca de $80 \%$ menor do que de um modo (TOMAÉL; MARTELETO, 2013).

Mesmo sendo embrionário no Brasil, estudos com enfoque na análise de redes two-mode, sobretudo no que diz respeito a investigação da produção acadêmica de artigos divulgados em eventos e ou periódicos científicos, têm sido desenvolvidos, assim como trabalhos de vários acadêmicos nos últimos anos acerca desta metodologia (GUARIDO FILHO; MACHADO-DA-SILVA, 2010; ROSSONI; GUARIDO FILHO, 2012; RIBEIRO; CORRÊA, 2014; RIBEIRO; SANTOS, 2017; RIBEIRO; CORRÊA; RIBEIRO, 2019), na área do conhecimento em Administração, mostrando, com isso, seu crescimento, mesmo ainda em um estágio inicial nas publicações com ênfase nas redes sociais.

Em síntese, a decisão para a seleção de redes de 1 ou 2 modos para a análise é definida pela finalidade do estudioso. Os objetivos da pesquisa 
e o que se pretende buscar ao final dela são determinantes para a definição do modo de análise em um estudo de redes sociais (TOMAÉL; MARTELETO, 2013). Ainda segundo os autores Tomaél e Marteleto (2013),

Muitas são as aplicações possíveis para redes de do is modos ou de afiliações, como, por exemplo: (i) composição de conselhos acadêmicos - conjuntos: 1) membros, 2) conselhos; (ii) membros de associações - conjuntos: 1) membros, 2) associações; (iii) pesquisadores e temas/campos de pesquisa - conjuntos: 1) pesquisadores, 2) campos/áreas do conhecimento (p. 252).

Por conseguinte, reitera-se e reforça-se que, para este trabalho científico, para se conseguir responder e alcançar a contento e com robustez a questão e o objetivo da pesquisa, foi decidido alicerçar e nortear a pergunta e o propósito do estudo pela análise de redes bipartidas, contribuindo, com isso, para a geração de informações e conhecimentos da área de estratégia à luz do evento 3Es sob a óptica das análises de redes sociais one e two-mode, colaborando com isso para o alargamento e a robustez deste campo do saber no âmbito científico literário nacional.

Porém, é também imprescindível dizer que, para se conseguir chegar as redes de colaboração dos atores envolvidos no processo de construção de saber científico, como no caso do objetivo deste estudo, se faz necessário as técnicas bibliométricas (CASSUNDÉ; BARBOSA; MENDONÇA, 2018), pois, por meio delas, é possível a exploração de textos, documentos e artigos científicos (FAVARETTO; FRANCISCO, 2017).

Proporcionando com isso a mensuração de dados e informações mediante índices bibliométricos (RIBEIRO; COSTA; FERREIRA, 2014) que, de maneira geral, alicerçam e mostram um caminho para se iniciar a construção das redes de cooperação de 1 e 2 modos dos atores (TOMAÉL; MARTELETO, 2013), sejam eles pesquisadores, instituições e ou temas (RIBEIRO, 2020), como foi o foco deste estudo.

\section{Procedimentos metodológicos}

O objetivo do estudo foi investigar o perfil e as características da produção científica divulgada no Evento 3Es, durante as Edições de 2003 a 2017, à luz das redes sociais one-mode e two-mode.

O referido congresso já foi investigado, direta ou indiretamente, em alguns estudos científicos com predominância ou não da análise de redes sociais (SARAIVA; CARRIERI, 2009; ROSSONI et al., 2010; ROCHA et al., 2011; WALTER; BACH; BARBOSA, 2012; WALTER et al., 2013; CUNHA; DEFINA; PASSADOR, 2014; SOARES et al., 2015; MARCON; BANDEIRA- 
DE-MELLO, 2016; VILELA; LOURENÇO; RESE, 2017; GUIMARÃES et al., 2018; TESTON; FILIPPIM, 2019).

Reitera-se e robustece-se com isso a importância e a relevância que o mencionado evento científico tem no panorama estratégico no Brasil. Porém, alerta-se que os artigos citados anteriormente, apesar de contemplarem estudos divulgados do evento $3 \mathrm{Es}$ em suas respectivas amostras de pesquisa, nenhum destes trabalhos enfocou de maneira integral no referido congresso, justificando, reiterando e fortalecendo assim a questão e o objetivo desta pesquisa.

\subsection{Procedimentos de coleta de dados}

A primeira fase do estudo, enfocou-se a técnica da bibliometria, onde realizou-se uma coleta de dados em artigos publicados no período de 2003 a 2017, perfazendo oito edições do evento científico 3Es em duas décadas, e o que corresponde a um levantamento longitudinal de 14 anos. Isto posto, evidencia-se que os dados foram coletados do congresso 3Es (Encontro de Estudos em Estratégia), evento "filho" da ANPAD. Ou seja, foram feitos os downloads de todos os artigos, cada um deles foi salvo em uma respectiva pasta no Microsoft Windows. Em seguida, foram planilhadas os indicadores bibliométricos: autores, instituições e temas (RIBEIRO, 2020), de cada artigo.

Os dados e as informações dos autores e de suas respectivas instituições foram retirados dos próprios artigos. Contudo, quando não estavam disponíveis, foram feitas as buscas no Google Scholar no ano em que o estudo foi publicado no evento 3Es. Ou seja, quando os dados e as informações não estavam acessíveis nos artigos, foram realizadas buscas no ano de publicação do artigo, pois, na maioria das vezes, o estudo foi também publicado em periódico científico, com isso, foi possível encontrar os dados que eram inviáveis para um determinado período de busca destas informações nos artigos.

Também, em algumas ocasiões, buscou-se para a confirmação destes dados, o acesso pela Plataforma Lattes de cada estudioso. Desta forma, foi possível a extração destes dados e informações, no que pertence aos nomes dos autores e de seus coautores e de suas respectivas instituições.

No que se refere aos temas, para análise e categorização dos mesmos, foi lido inicialmente os títulos dos artigos, quando não era possível se saber o tema específico, leram-se as palavras-chave para um possível norte deste tema, e, não sendo aceitável a categorização deste assunto, leu-se o resumo deste artigo para situar de maneira a evitar viés e as incoerências na análise e a classificação dos temas nos artigos. Para melhor norte, embasamento e classificação dos temas deste estudo, usaram-se as pesquisas de Bertero, Vasconcelos e Binder (2003), Ferreira 
et al. (2015), Marcon e Bandeira-de-Mello (2016), Ribeiro e Corrêa (2018).

$\mathrm{Na}$ segunda fase da pesquisa, foram tabuladas e mensuradas as variáveis por meio das matrizes one-mode: autores, instituições de ensino superior; e a matriz de análise de redes two-mode: temas e autores. Do download dos artigos, até a finalização das redes dos atores se deu da data de 07-02-2020 até 05-03-2020.

\subsection{Procedimentos de análise de dados}

Este procedimento admitiu identificar 929 artigos publicados nas oito edições do citado evento. Foi realizada a análise dos dados por meio dos seguintes indicadores sociométricos: (I) redes sociais das instituições (centralidade de grau); (II) redes sociais das instituições (centralidade de intermediação); (III) redes de coautoria; (IV) redes de coautoria (centralidade de grau); (V) redes de coautoria (centralidade de intermediação); e (VI) redes sociais two-mode (temas e autores). Estes indicadores foram mensurados utilizando os softwares Microsoft Excel 2007 (fase da bibliometria e fase da sociometria). E os indicadores de redes sociais foram aferidos utilizando o software UCINET e visualizados pelo software NetDraw.

Para as redes sociais dos atores (autores e instituições) one-mode foram feitas no software UCINET, com ajuda do software Microsoft Excel 2007, pois, os dados dos atores foram planilhados um a um em uma matriz simétrica, sendo, a posteriori, os dados copiados e colados na matriz do software UCINET e visualizados, em seguida, no software NetDraw, gerando, com isso, as redes de colaboração one-mode, enfocando as centralidades de grau e de intermediação dos pesquisadores e instituições por década.

No que concerne a construção das redes sociais one-mode, o estudo dos pesquisadores Ribeiro e Ribeiro (2019) obedeceu, de maneira idêntica, o passo a passo da constituição das planilhas, matrizes, das redes de colaboração dos atores e de suas respectivas visualizações.

É importante salientar que se optou por dividir as redes de cooperação por década, em decorrência da quantidade grande de pesquisadores identificados no estudo, e para que fosse possível uma melhor visualização destes nas respectivas redes de coautoria. E, desta maneira, focou-se por se fazer o mesmo com a rede social das instituições, padronizando-a com as redes de coautoria, ou seja, deixando-as divididas por década.

De maneira similar, para se conseguir criar as redes two-mode usou-se novamente o mesmo comportamento nas planilhas, mas agora com os atores (temas e autores). Desta forma, a planilha gerou uma matriz bipartida (WASSERMAN; FAUST, 1994), deixando no eixo " $y$ " os 
autores e no eixo " $x$ " os temas (MACHADO JUNIOR et al., 2016). Em seguida, foram copiados os dados da planilha no software UCINET e visualizados, a posteriori, as redes de colaboração two-mode no software NetDraw (RIBEIRO; CORRÊA; RIBEIRO, 2019; RIBEIRO, 2020). Salientase que,para fomentar as visualizações dos temas que ficaram em destaque em cada década, se usou a propriedade da centralidade de grau.

\section{Análise e discussão dos resultados}

Esta seção abordará a análise e discussão dos resultados dos 929 artigos publicados nas duas décadas do evento científico 3Es à luz das redes sociais one-mode (Figuras 1, 2, 3, 4 e 5) e two-mode (Figura $6)$.Cada uma destas figuras foi subdividida em décadas.

\subsection{Redes sociais das instituições (centralidade de grau)}

As Figura 1.1 e 1.2evidenciam as redes sociais das 224 instituições identificadas neste estudo, divididas por década (Década 1 - 2003 a 2009 - Figura 1.1; Década 2 - 2011 a 2017 - Figura 1.2) e à luz da centralidade de grau.

Figura 1.1: Redes sociais das instituições da década 2003 a 2009 à luz da centralidade de grau

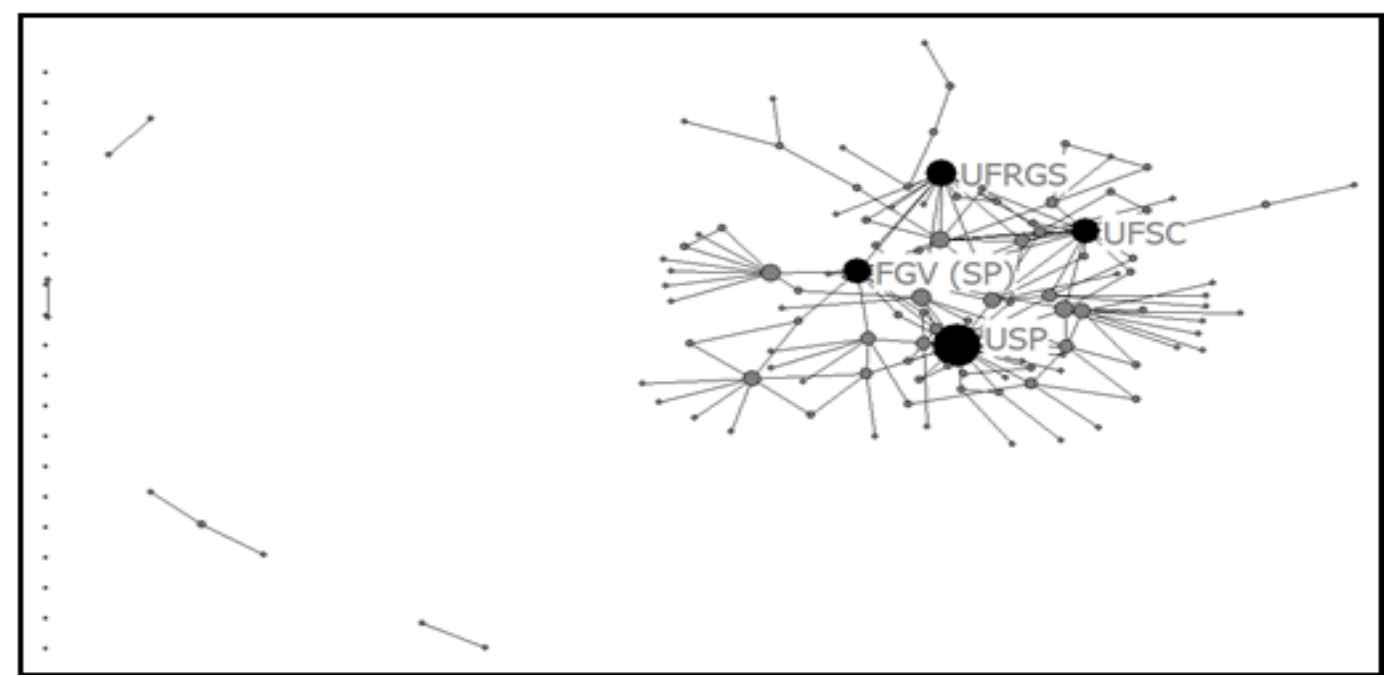

Fonte: Dados da pesquisa

Analisando a Figura 1.1, têm-se as redes das instituições que publicaram na primeira década de vida do 3Es, colocando ênfase nas IESs com maior centralidade de grau, são elas: USP, UFRGS, UFSC e FGV (SP).Agora, analisando a Figura 1.2, visualiza-se a rede social das IESs com maior centralidade de grau na segunda década do 3Es, sendo que as instituições que se destacam nesta década são: USP, FGV (SP), UNIVALI, UNINOVE, também são citadas as seguintes IESs: UFPR, UNISINOS, UFSM, ESPM e UFRGS. 
As pesquisas dos estudiosos Bertero, Vasconcelos e Binder (2003), Schneider et al. (2009), Walter et al. (2010) e Ribeiro, Muritiba e Muritiba (2012) corroboram, de maneira análoga, com os achados desta seção, ou seja, no que se adere as instituições em realce neste estudo afetando suas respectivas representatividades na produção científica de temas relacionados a área de estratégia no Brasil.

Figura 1.2: Redes sociais das instituições da década 2011 a 2017 à luz da centralidade de grau

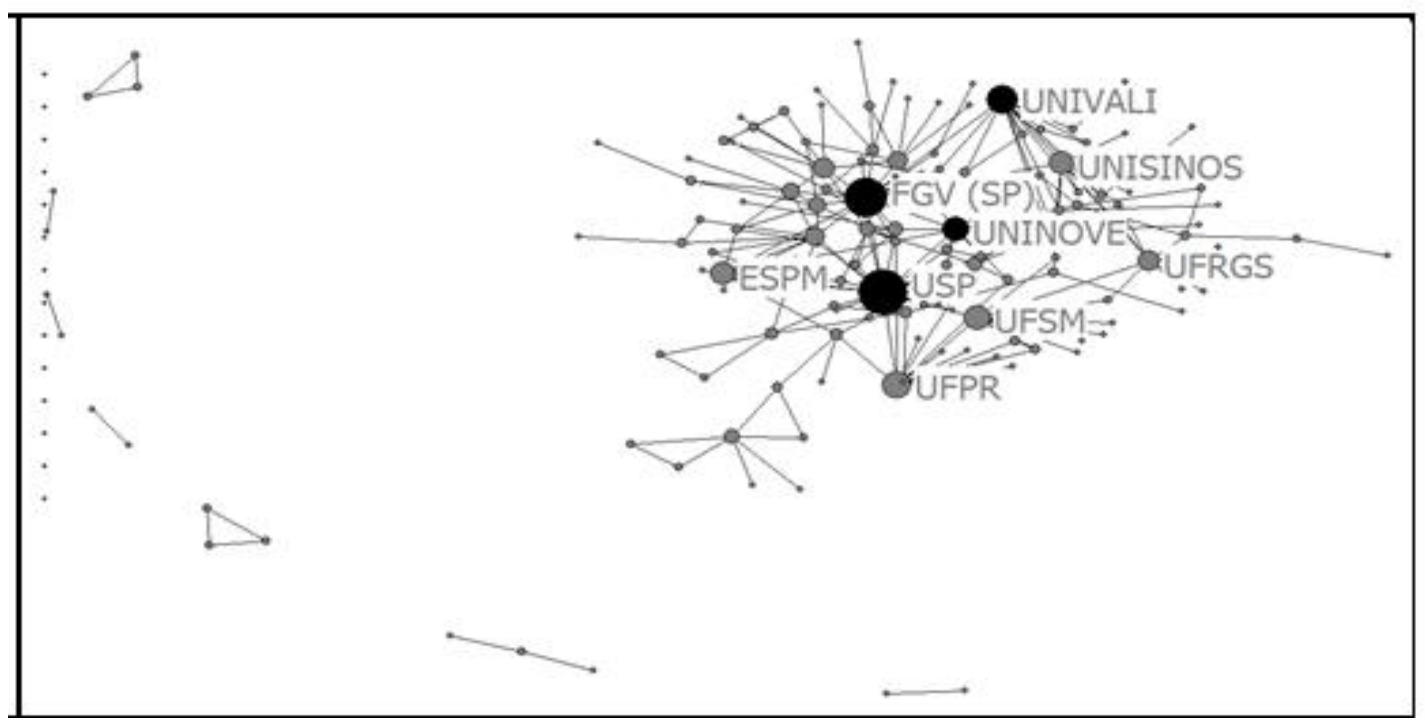

Fonte: Dados da pesquisa

O que é possível notar é que as instituições: USP, FGV (SP) e UFRGS são colocadas em relevo em ambas as décadas, o que representa a envergadura e a proeminência destas instituições na produção científica sobre estratégia à luz do evento 3Es. No tocante a proficuidade das instituições,todas as que estão entre as mais centrais desta pesquisa, também surgem como as mais produtivas, o que nos leva a entender e compreender que, a proficuidade destas instituições influenciam diretamente em suas respectivas redes sociais de colaboração, sobretudo no que tange a centralidade de grau (CRUZ et al., 2011; MORAES; FURTADO; TOMAÉL, 2015).

As informações contempladas nesta seção contribuem para manifestar as IESs com maior relevância no campo da produção acadêmica de estudos sobre a área de estratégia, influenciando com isso a difusão, disseminação e socialização de temas que interagem, direta ou indiretamente, com o campo do conhecimento estratégia, impactando em seu maior crescimento e desenvolvimento na literatura científica nacional.

Não obstante a isso, as instituições que ficaram em relevo, nesta seção, são representadas respectivamente por programas de pósgraduação em Administração que estão entre os mais importantes do 
país, colaborando com isso para alargar e robustecer, como dito antes, a área de estratégia no Brasil.

\subsection{Redes sociais das instituições (centralidade de intermediação)}

As Figura 2.1e Figura 2.2 visualizam as redes sociais das 224 instituições identificadas neste estudo, divididas por década (Década 1 2003 a 2009 - Figura 2.1; Década 2 - 2011 a 2017 - Figura 2.2) e à luz da centralidade de intermediação.

Figura 2.1: Redes sociais das instituições da década 2003 a 2009 à luz da centralidade de intermediação

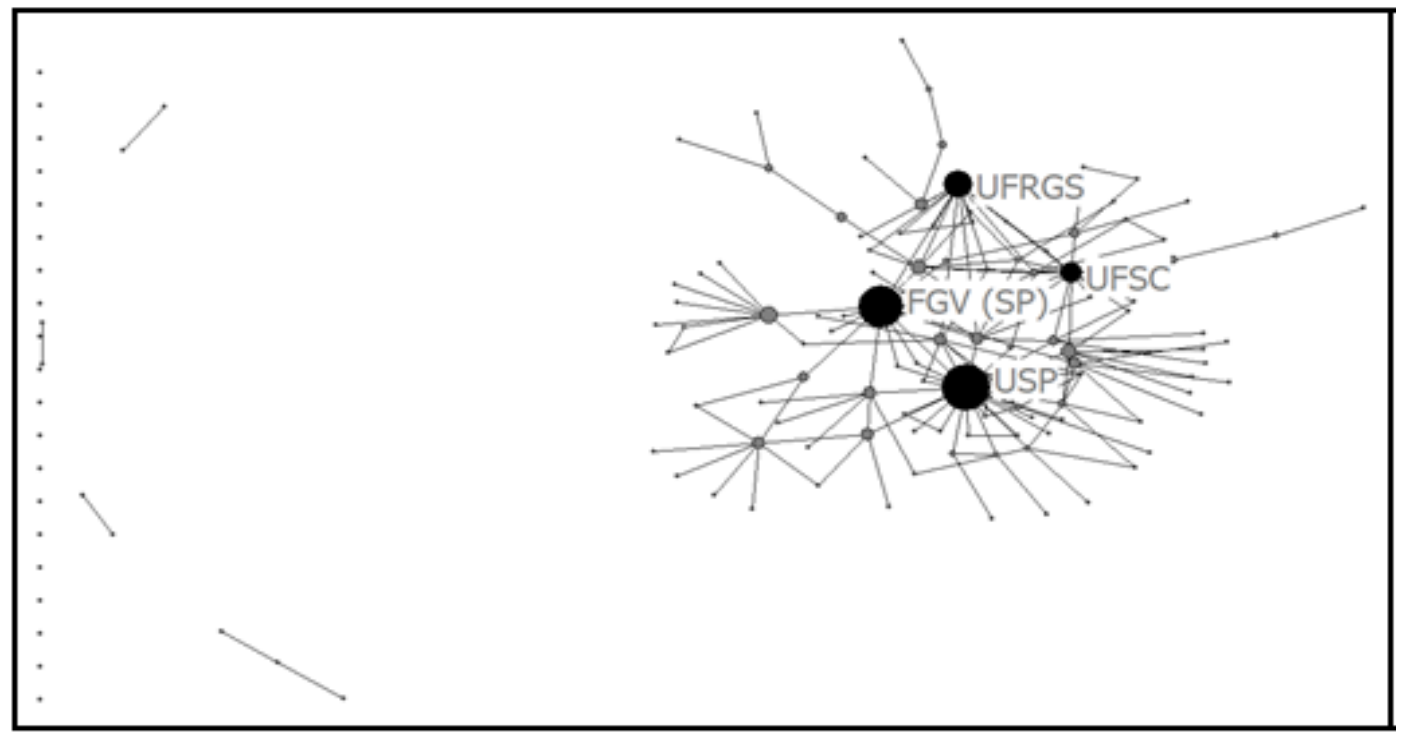

Fonte: Dados da pesquisa

As redes das instituições contempladas nas Figuras 2.1 e 2.2 são análogas as da Figura 1.1 e Figura 1.2, porém, com ressalva de que, ao invés de se enfocar na centralidade de grau das IES (Figuras 1.1 e 1.2), se colocou em relevo a centralidade de intermediação, contemplando com isso as IESs com maior contribuindo no que se refere ao caminho para se adentrar e, concomitantemente, criar conhecimento no que importa a área de estratégia no Brasil. 
Figura 2.2: Redes sociais das instituições da década 2011 a 2017 à luz da centralidade de intermediação

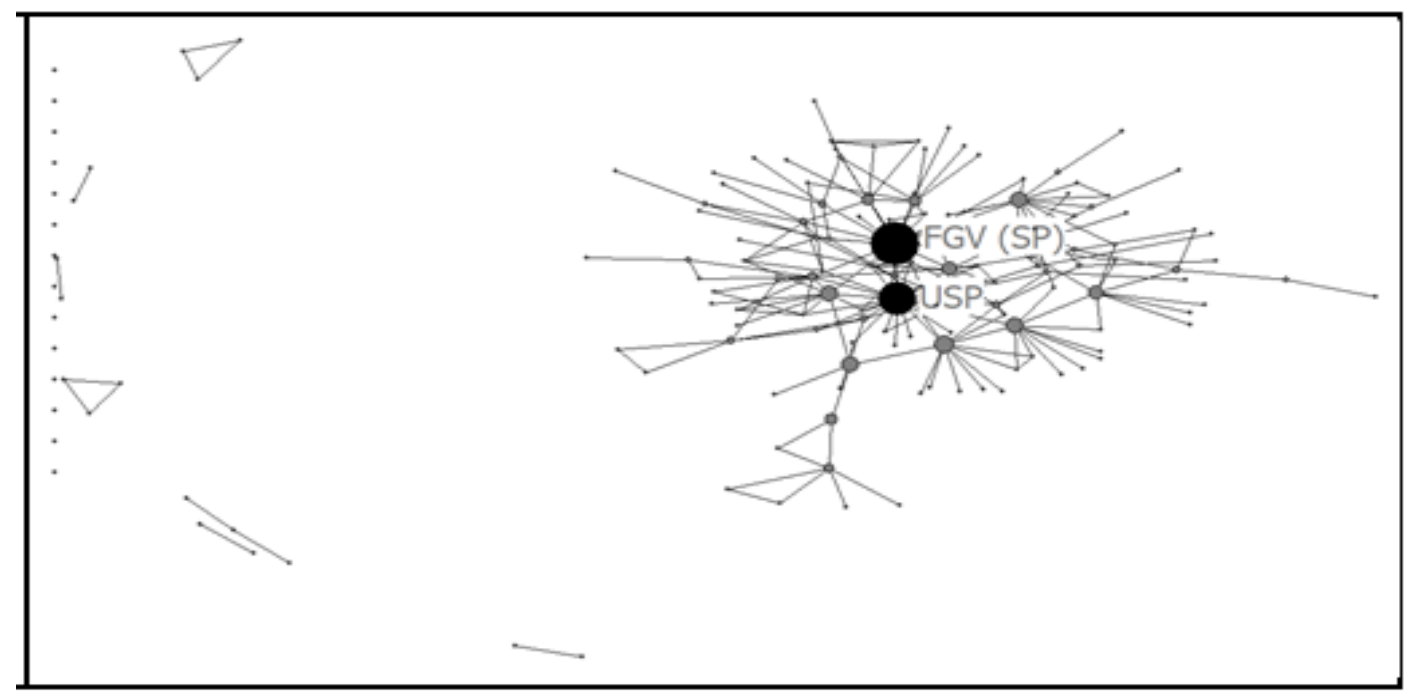

Fonte: Dados da pesquisa

Isto dito, da esquerda para a direita, no que corresponde a primeira década de vida do 3Es, destacam-se as seguintes IESs: USP, FGV (SP), UFRGS e UFSC (por coincidência ou não, são as mesmas que ficaram em realce na Figura 1.1 na primeira década). $E$, no que pertence a segunda década (2011 a 2017), aparecem as instituições: USP e FGV (SP).

De maneira geral, constata-se que as IES: USP e FGV (SP) são aquelas que cooperam com as demais IESs norteando-as para a construção do saber acadêmico no que está pertinente a área de estratégia, ou seja, são as instituições com maior centralidade de intermediação (CRUZ et al., 2011; MORAES; FURTADO; TOMAÉL, 2015) para este estudo que enfatiza o evento científico 3Es.

De maneira macro, ao verificar as Figuras 1.1 e 1.2 e 2.1 e 2.2 desta pesquisa, têm-se um predomínio das instituições das regiões Sudeste e Sul do Brasil quanto a relevância, envergadura e destaque na centralidade de grau e de intermediação, mostrando e reiterando com isso o alicerce e o norte que estas instituições desempenham na contribuição da produção acadêmica dos temas e, consequentemente, para a área de estratégia nacional, em especial as instituições USP e FGV (SP) que também ficaram em evidência na proficuidade da produção científica nos estudos divulgados no 3Es em suas duas décadas de vida.

Outra característica das redes das IESs visualizadas nas Figuras 1.1 e 1.2 e 2.1 e 2.2 deste estudo é a apresentação de redes esparsas, influenciando em uma alta centralidade de grau e de intermediação, sendo refletida nas instituições que ficaram em destaque nas citadas centralidades. Tal fato é confirmado no estudo de Ribeiro e Corrêa (2018) que identificou redes das instituições dispersas, provocando um alargamento da centralidade das seguintes IESs: UNINOVE, USP e FGV 
(SP). Tal descoberta é corroborado com os resultados desta pesquisa, especialmente no que obedece às instituições USP e FGV (SP) que também ficaram em evidência nas centralidades de grau e de intermediação deste estudo respectivamente.

No entanto, para se conseguir colocar estas instituições em destaque a nível brasileiro na produção científica da área de estratégia, os estudiosos, docentes, pesquisadores seniores ou iniciantes são preponderantes para tal, pois, mediante pesquisas individuais, de iniciação científica, orientações de mestrado e ou doutorado, e supervisões de pós-doutorado, atrelado a grupos de pesquisas consolidados e ou emergentes de programas de pós-graduação em Administração, legitimados no panorama brasileiro, ajudam a performar estas IESs, colocando-as em evidência e relevo. Posto isto, as Figuras 3, 4 e 5 visualizam as redes de coautoria dos pesquisadores identificados neste estudo.

\subsection{Redes de coautoria}

A Figura 3 contempla as redes sociais dos 1615 autores identificados neste trabalho, divididos por década (Década 1 - 2003 a 2009; Década 2 - 2011 a 2017 da esquerda para a direita).

Figura 3: Redes de coautoria por década

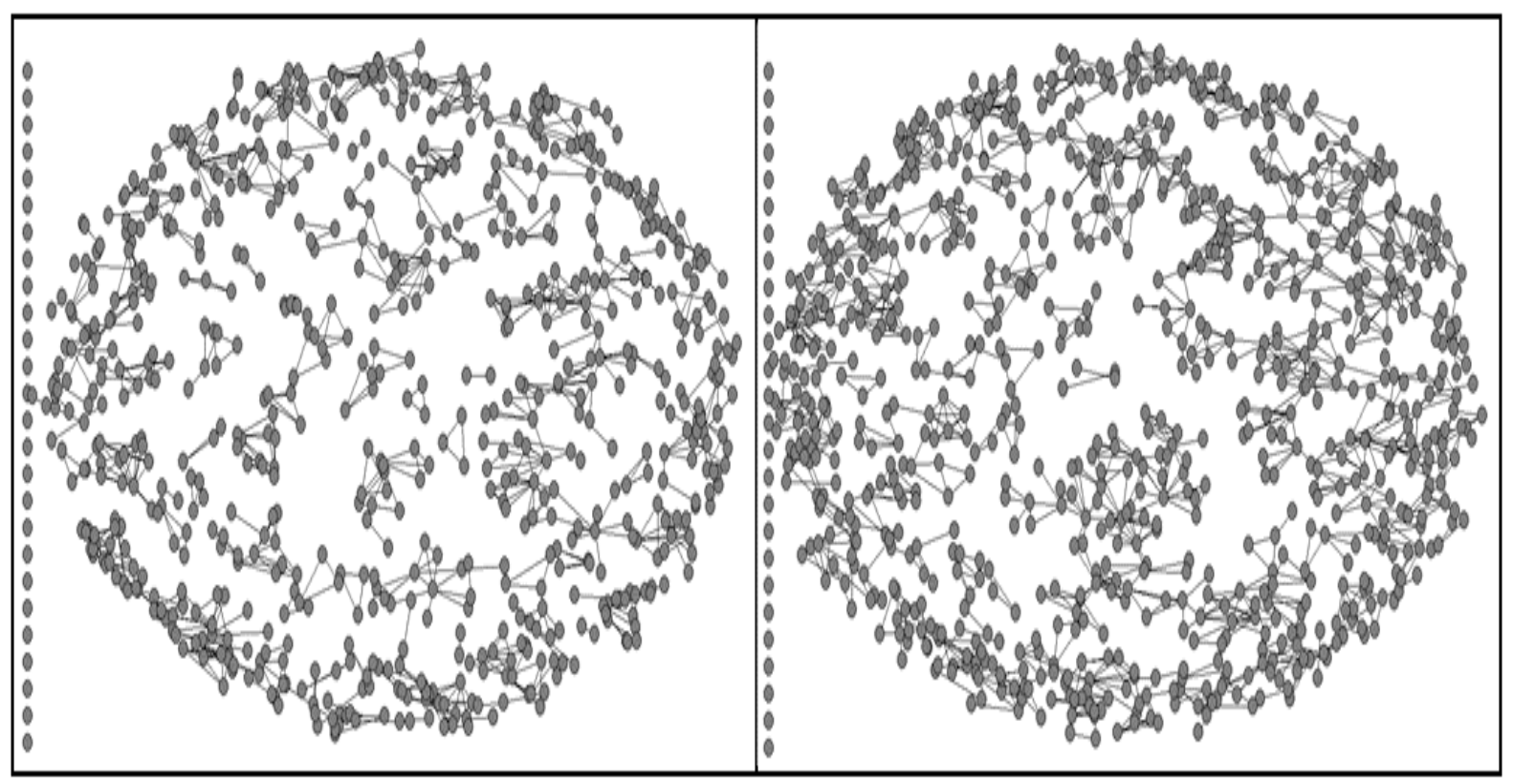

Fonte: Dados da pesquisa

A Figura 3 traz em seu bojo duas redes de coautoria, uma para cada década. A primeira década (visualiza-se a rede da esquerda para a direita) é composta de 917 pesquisadores; e a segunda década, que a rede é vislumbrada da direita para a esquerda, evidencia 1081 estudiosos. 
De certo que, muitos destes acadêmicos estão compondo em ambas as redes de coautoria, porém, é notório observar um aumento do número de acadêmicos de uma década para a outra, sendo um indício de que o evento ora em investigação abarcou e possibilitou a entrada de novos autores e, consequentemente, de novas instituições de ensino (Figuras 2.1 e 2.2), contribuindo e influenciando no alargamento e robustecimento da produção científica da área de estratégia em âmbito nacional.

Tal apuração, exposta na Figura 3, também é um indicativo de que, tanto nas redes das IES, como sobretudo nas redes de coautoria, ocorrera uma ampliação em ambas, fomentando com isso as colaborações científicas sobre o campo da estratégia, podendo com isso impactar no surgimento, na construção, evolução, consolidação e ou legitimidade dos grupos de pesquisas respectivos dos programas de pós-graduação em Administração que são oriundos das IESs identificadas e, a posteriori, poderão compor a rede social destas instituições, fomentando e criando valor acadêmico mediante a publicação e disseminação de temáticas relacionadas a estratégia, engrandecendo simultaneamente a área do conhecimento Administração no Brasil.

Contudo, apesar do alargamento do número de autores de uma década para a outra, existem redes esparsas, o que pode incorrer em grupos de autores mais centrais (WATANABE; GOMES; HOFFMANN, 2013; ANDRADE et al., 2016). Estas redes dispersas sugerem baixa densidade das redes, limitando a cooperação entre os pesquisadores (BUENO et al., 2014; RIBEIRO; COSTA; FERREIRA, 2014), apesar, repito, do crescimento dos pesquisadores de uma década para a outra.

\subsection{Redes de coautoria (centralidade de grau)}

A Figura 4 é análoga a Figura 3 dividida por década (Década 1 2003 a 2009; Década 2 - 2011 a 2017 da esquerda para a direita) sob a óptica da centralidade de grau. 
Figura 4: Redes de coautoria por década à luz da centralidade de grau

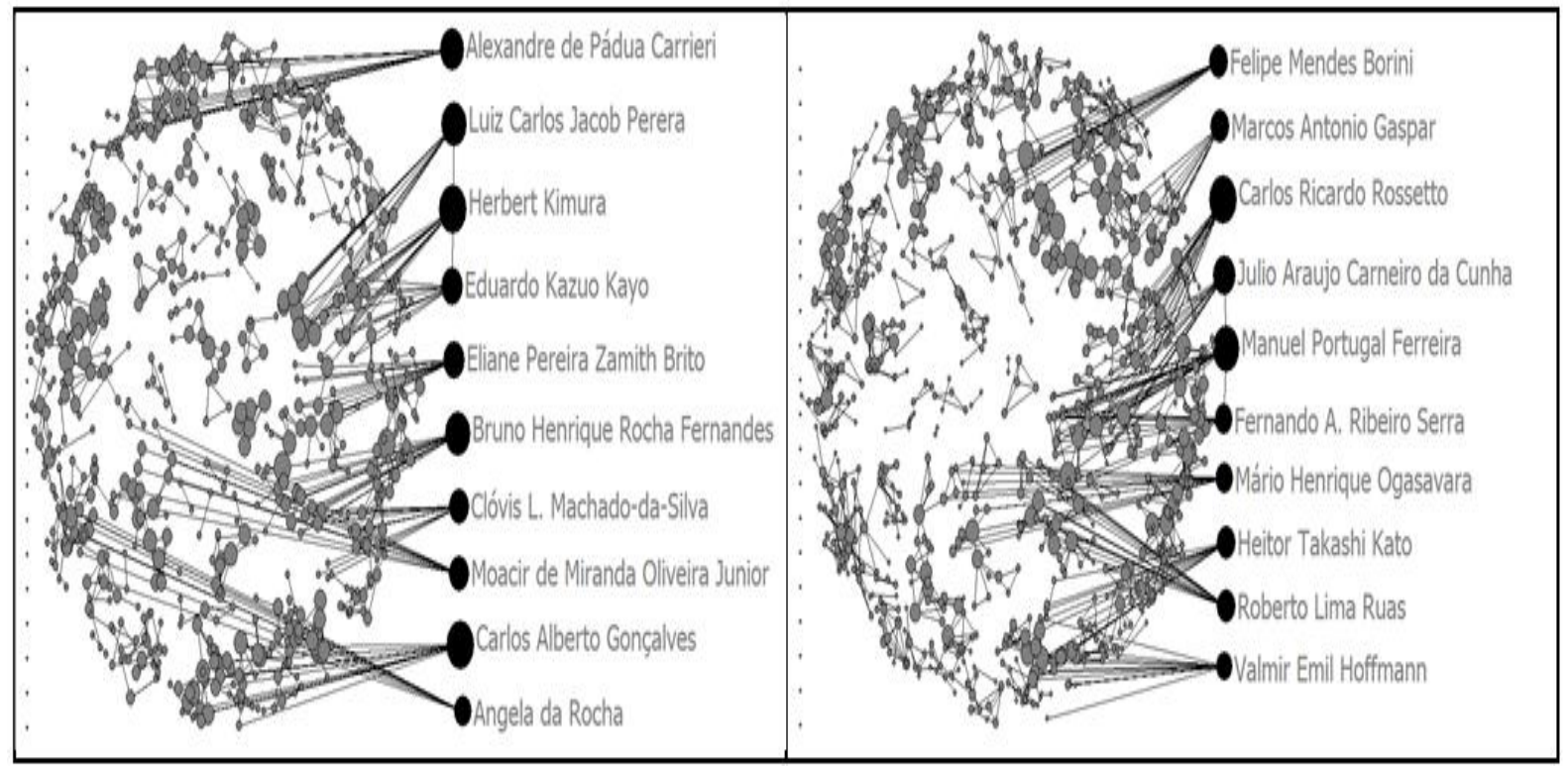

Fonte: Dados da pesquisa

Os autores mais centrais deste estudo, na primeira década do evento em investigação, são: Alexandre de Pádua Carrieri, Luiz Carlos Jacob Perera, Herbert Kimura, Eduardo Kazuo Kayo, Eliane Pereira Zamith Brito, Bruno Henrique Rocha Fernandes, Clóvis L. Machado-da-Silva, Moacir de Miranda Oliveira Junior, Carlos Alberto Gonçalves e Angela da Rocha. Já na segunda década desta pesquisa, os estudiosos com maior centralidade de grau são: Felipe Mendes Borini, Marcos Antonio Gaspar, Carlos Ricardo Rosseto, Julio Araujo Carneiro da Cunha, Manuel Portugal Ferreira, Fernando A. Ribeiro Serra, Mário Henrique Ogasavara, Heitor Takashi Kato, Roberto Lima Ruas e Valmir Emil Hoffmann. É importante salientar que os autores enfatizados aqui não estão por ordem crescente ou decrescente e, sim, evidenciados de forma aleatória.

Posto isto, a primeira informação que fica evidente ao ler os autores mais centrais nas duas décadas é que nenhum deles se destacou nas duas décadas, ou seja, todos os pesquisadores em relevo nas duas décadas apareceram apenas uma vez. Tal fato pode sugerir que uma heterogeneidade dos autores mais centrais no que se refere a área de estratégia e aos assuntos nela contemplados no 3Es; isso mostra uma rotatividade no que interessa a relevância dos acadêmicos na produção científica do campo do saber em estratégia, contribuindo para sua evolução e, consequentemente, legitimidade na literatura científica nacional (ROSSONI et al., 2010).

Quanto mais pesquisadores se destacam como autores centrais, ou seja, de relevância e importância na área de estratégia, mais propensa esta área fica no que se conecta fomentar as redes de colaboração dos atores (pesquisadores e suas respectivas IESs), influenciando e 
contribuindo para uma maior difusão, disseminação e socialização das temáticas relacionadas à estratégia, cooperando para otimizar sua performance como campo em destaque na área de Administração no Brasil.

De maneira geral, os dados e as informações contempladas na visualização das redes de coautoria com enfoque na centralidade de grau neste estudo contribuem para saber, entender e compreender quais são os pesquisadores, acadêmicos, estudiosos da área de estratégia que se destacam como atores centrais, contribuindo para impactar na criação de valor acadêmico, mediante a construção de conhecimento científico, por meio de temáticas essenciais para engrandecer, robustecer e alargar a área de estratégia $e$, consequentemente, o campo do saber em Administração no Brasil.

\subsection{Redes de coautoria (centralidade de intermediação)}

A Figura 5 é análoga a Figura 3 dividida por década (Década 1 2003 a 2009; Década 2 - 2011 a 2017 da esquerda para a direita) sob a ótica da centralidade de intermediação.

Figura 5: Redes de coautoria por década à luz da centralidade de intermediação

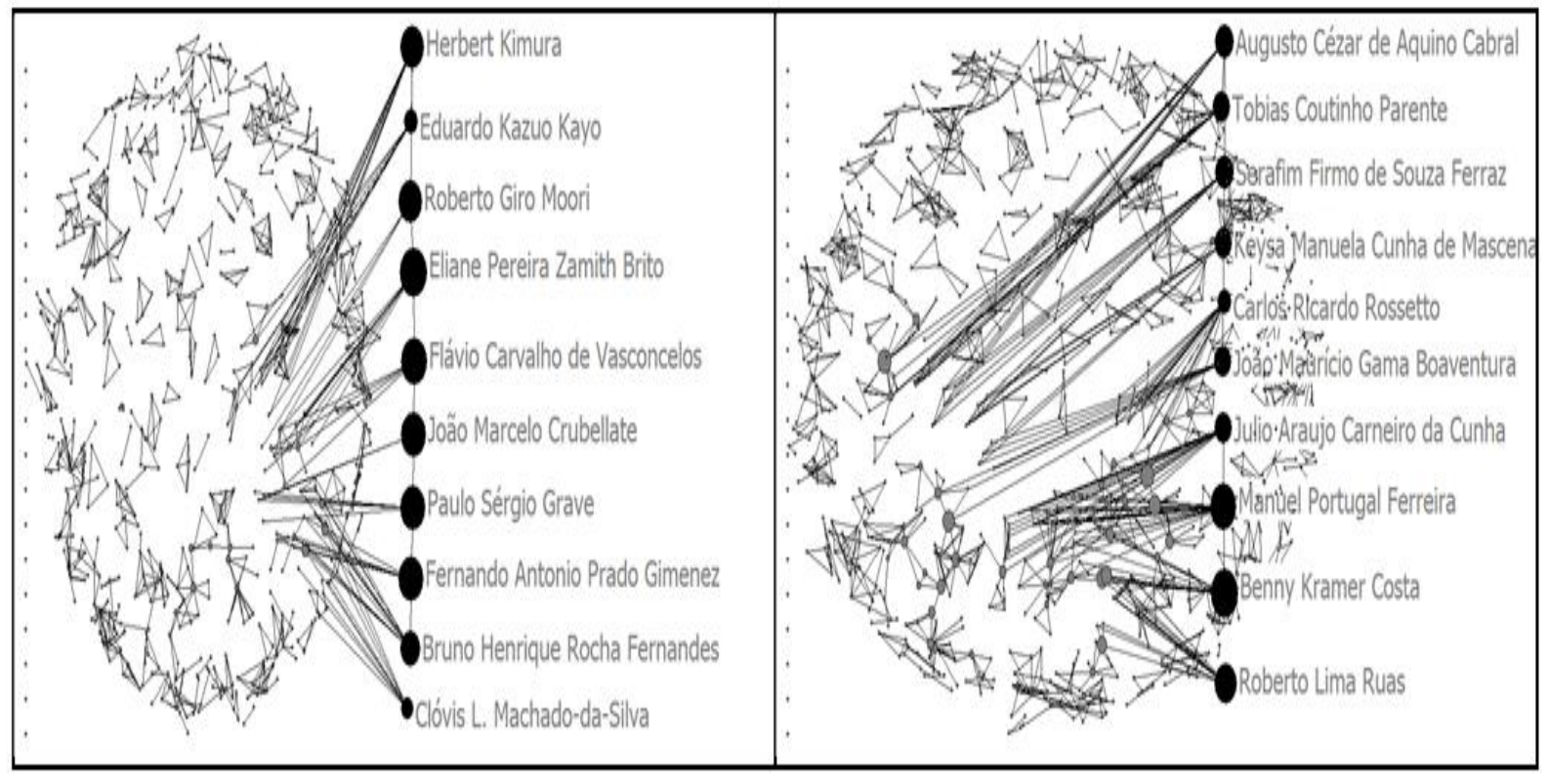

Fonte: Dados da pesquisa

Os autores com maior centralidade de intermediação na primeira década (visualizada da esquerda para a direita) de vida do 3Es são: Herbert Kimura, Eduardo Kazuo Kayo, Roberto Giro Moori, Eliane Pereira Zamith Brito, Flávio Carvalho de Vasconcelos, João Marcelo Crubellate, Paulo Sérgio Grave, Fernando Antonio Prado Gimenez, Bruno Henrique Rocha Fernandes e Clóvis L. Machado-da-Silva. 
Já os pesquisadores que ficaram em realce na segunda década (visualiza-se da direita para a esquerda) no evento em investigação, são: Augusto Cézar de Aquino Cabral, Tobias Coutinho Parente, Serafim Firmo de Souza Ferraz, Keysa Manuela Cunha de Mascena, Carlos Ricardo Rosseto, João Maurício Gama Boaventura, Julio Araujo Carneiro da Cunha, Manuel Portugal Ferreira, Benny Kramer Costa e Roberto Lima Ruas.É importante ressaltar que os pesquisadores enfocados aqui não estão por ordem crescente ou decrescente e, sim, contemplados de maneira aleatória.

Como ocorrerá na Figura 4, ou seja, na seção anterior deste estudo, nenhum dos autores que ficaram em evidência na primeira década de vida do 3Es (Figura 5), no que se vincula a centralidade intermediação, apareceu em relevo na segunda década, e vice-versa, o que nos faz entender e compreender que houve uma ratificação e confirmação de que novos estudiosos surgirão no painel da área de estratégia no Brasil, à luz do congresso em investigação, contribuindo para que a citado campo do saber se propague ainda mais, mediante uma maior robustez e alargamento das redes de colaboração da produção científica em estratégia, mediante as temáticas nela relacionadas.

Condensando as Figuras 4 e 5 desta pesquisa, é salutar colocar em foco os autores por década e no que se refere as centralidades. Em outras palavras, os estudiosos que ficaram com maior destaque na primeira década do estudo em relação as centralidades de grau e de intermediação são: Herbert Kimura, Eduardo Kazuo Kayo, Eliane Pereira Zamith Brito, Bruno Henrique Rocha Fernandes e Clóvis L. Machado-da-Silva. E, no que toca a segunda década do evento em análise, os pesquisadores que ficaram ainda mais em destaque sob a ótica das centralidades de grau e de intermediação são: Carlos Ricardo Rosseto, Julio Araujo Carneiro da Cunha, Manuel Portugal Ferreira e Roberto Lima Ruas.

$E$ destes acadêmicos, englobando as duas décadas $e$ as centralidades em foco, somente três também surgem como os mais profícuos desta pesquisa, são eles: Carlos Ricardo Rossetto (com 12 artigos publicados), Clóvis L. Machado-da-Silva (nove publicações) e Manuel Portugal Ferreira (oito divulgações). Os estudos de Bertero, Vasconcelos e Binder (2003) e Walter et al. (2010) também colocaram o autor Clóvis L. Machado-da-Silva em evidência na área de estratégia.

Tal apuramento mostra que, nem sempre ser profícuo sobre algum tema ou área do conhecimento, o torna autor central, em decorrência de que a centralidade, seja ela de grau seja de intermediação, está relacionado a quantidade de pesquisadores que se conectam em parceria com estes estudiosos mais produtivos, influenciando com isso diretamente em suas respectivas centralidades, e, neste estudo, somente três pesquisadores conseguiram alinhar suas respectivas proficuidades na 
produção científica na área de estratégia e, as centralidades de grau e de intermediação.

Este resultado também pode acender a possibilidade e a necessidade de que os estudiosos, sobretudo os mais relevantes e importantes para a difusão e socialização de temas versados na área de estratégia, alarguem e robusteçam suas parcerias, contribuindo, consequentemente, para a construção de novas ideias, conhecimentos e saberes e, concomitantemente, na otimização de suas centralidades respectivas na área de estratégia, à luz do evento cientifico 3Es.

\subsection{Redes sociais two-mode (temas e autores)}

A Figura 6 mostra a rede two-mode com os atores (autores e temas), dividida por década (Década 1 - 2003 a 2009; Década 2 - 2011 a 2017 da esquerda para a direita) sob a ótica da centralidade de grau.

Figura 6: Redes two-mode (autores e temas) por década à luz da centralidade de grau

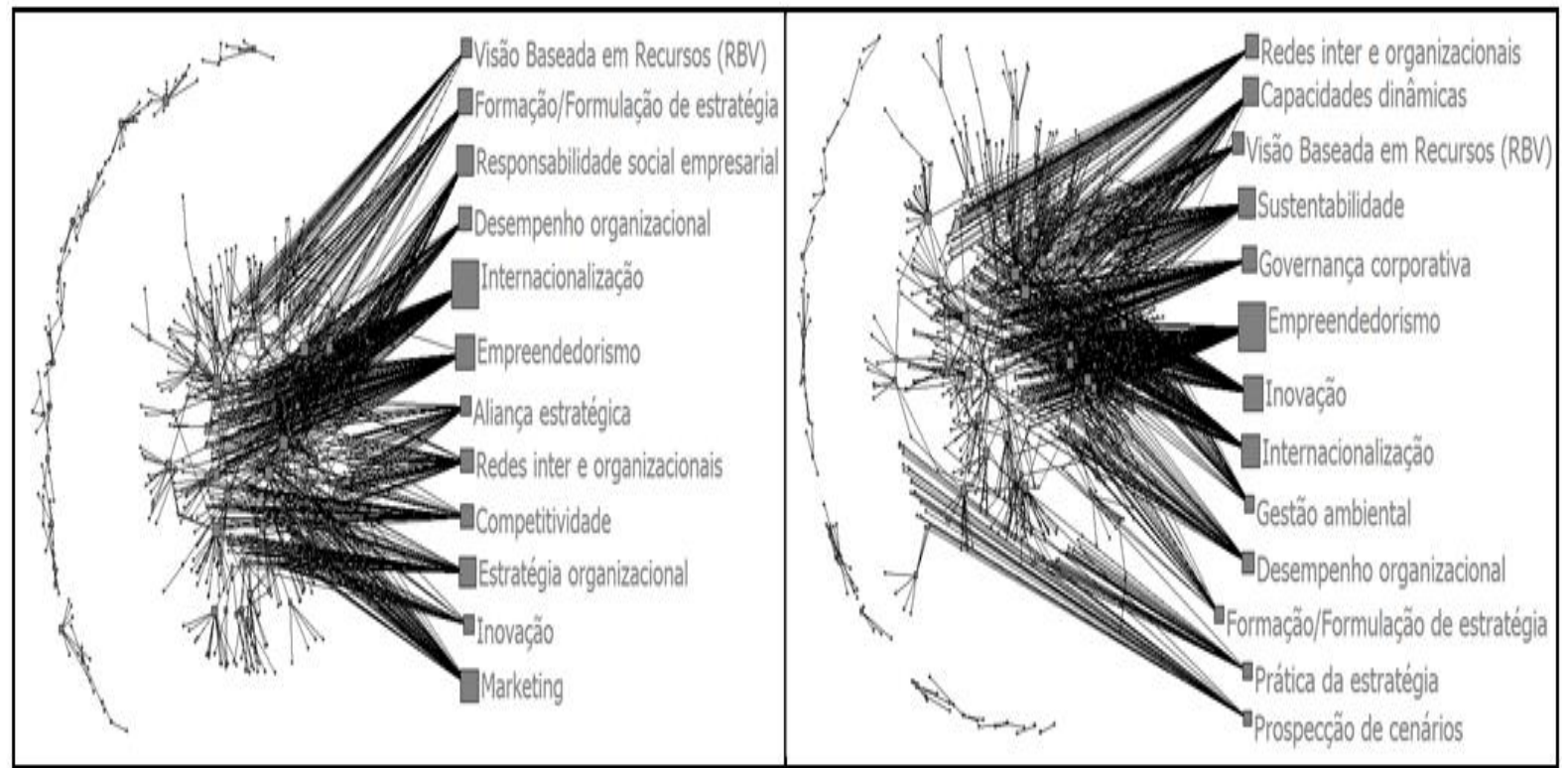

Fonte: Dados da pesquisa

Posto isto, os temas que mais chamam a atenção dos pesquisadores, e, consequentemente, se tornam os mais publicados, na primeira década (visualizada da esquerda para a direita) são: visão baseada em recursos, formulação de estratégia, responsabilidade social empresarial, desempenho organizacional, internacionalização, empreendedorismo, aliança estratégica, redes inter e organizacionais, competitividade, estratégia organizacional, inovação e marketing. Em relação a segunda década (visualizada da direita para a esquerda), os temas que ficaram em destaque são: redes inter e organizacionais, capacidades dinâmicas, visão baseada em recursos, sustentabilidade, governança corporativa, empreendedorismo, inovação, 
internacionalização, gestão ambiental, desempenho organizacional, formulação de estratégia, prática de estratégia, prospecção de cenários.

Primeiramente, observa-se que os temas: responsabilidade social empresarial, aliança estratégica, competitividade e inovação ficaram somente em realce na primeira década do estudo. Já na segunda década, as temáticas que ficaram em relevo somente nesta década foram: capacidades dinâmicas, sustentabilidade, governança corporativa, gestão ambiental, prática de estratégia e prospecção de cenários.

$E$, por fim, os temas que ficaram em evidência em ambas as décadas foram: visão baseada em recursos, formulação de estratégia, desempenho organizacional, internacionalização, empreendedorismo, redes inter e organizacionais e inovação. $E$, destes, os cinco últimos assuntos estão entre os Top Five da produção científica nas duas décadas de vida do $3 E s$.

Os estudos de Bertero, Vasconcelos e Binder (2003), Ferreira et al. (2015), Marcon e Bandeira-de-Mello (2016) e Ribeiro e Corrêa (2018) corroboraram com os achados deste estudo, em especial os trabalhos dos estudiosos Ribeiro e Corrêa (2018) que investigaram a representatividade e as particularidades da produção acadêmica divulgada pela Revista Ibero-Americana de Estratégia durante o período de 2002 a 2015.

As confirmações destes citados estudos vão ao encontro no que se refere aos temas mais abordados e publicados na área de estratégia no Brasil. E tal fato, permite entender e compreender que os enfatizados temas estão no estado da arte da produção acadêmica da área de estratégia. Estas temáticas que ficaram em evidência neste estudo, ajudam a entender e a compreender a heterogeneidade e a horizontalidade que a área do conhecimento estratégia tem para com os estudos do campo do saber Administração, contribuindo para sua legitimidade na área acadêmica em revistas e em congressos científicos, como no caso do 3Es (evento ora investigado), e, concomitantemente, no âmbito internacional.

Ribeiro e Corrêa (2018) identificaram 93 temas, sendo que oito ficaram em destaque: internacionalização, estratégias, sustentabilidade, empreendedorismo, inovação, balanced scorecard, gestão ambiental e responsabilidade social.Destes oito assuntos, três aparecem neste estudo com os mais profícuos, são eles: internacionalização, empreendedorismo e inovação.

O que mostra, ratifica, reforça e reitera a importância e a preponderância destes temas na área de estratégia no que atribui às suas respectivas produções científicas, sendo elas divulgadas, socializadas e disseminadas tanto em periódico, como no caso da revista RIAE investigada por Ribeiro e Corrêa (2018), como também no bojo das publicações difundidas nas duas décadas de vida do evento científico 3Es. 
Dito isto, é salutar afirmar que os autores da área de estratégia buscam temas (MARCON; BANDEIRA-DE-MELLO, 2016) como estes em destaque neste estudo para publicar no Brasil.

Em outra pesquisa de Ribeiro e Corrêa (2014), agora analisando o estado da arte da produção científica da Revista de Administração Mackenzie de 2008 a 2012, também constataram um destaque dos temas internacionalização, empreendedorismo e inovação nas publicações da citada revista, reforçando com isso a relevância e importância destas temáticas, não somente no contexto da área de estratégia, mas sobretudo no âmbito do campo do conhecimento Administração na literatura cientifica nacional, à luz dos periódicos científicos.

No estudo de Machado-da-Silva e Rossoni (2007), onde os autores procuraram verificar o nível de coesão estrutural dos pesquisadores da área de estratégia no Brasil, condicionando a construção do conhecimento científico no citado campo, observou-se uma heterogeneidade de temas de pesquisa, onde ficaram em evidência as seguintes temáticas: empreendedorismo, internacionalização, redes inter e organizacionais, competitividade e inovação.

Tais resultados corroboram com os achados deste estudo, em especial com esta seção, abordando os temas que estavam em destaque no contexto científico em estratégia a cerca de 13 anos atrás (época em que o estudo foi publicado pelos referidos estudiosos), mas passados mais de uma década, ainda continuam (os temas) em realce na academia, conhecimentos estes referendados mediante as publicações das duas décadas do 3Es.

Em resumo, as informações manifestadas nesta seção propagam os temas mais publicados e ou procurados para serem investigados pelos estudiosos da área de estratégia à luz do 3Es, evidenciando com isso a heterogeneidade de temas identificados neste estudo (127 no total), contudo, contemplando os mais aclamados, ou seja, os mais escolhidos pelos pesquisadores para que seus respectivos estudos sejam aceitos e publicados, em eventos científicos, como no caso do congresso científico em investigação neste trabalho.

Conhecer as temáticas mais manifestadas pelos autores do campo da estratégia, possibilita avançar por meio da construção de novas pesquisas relacionadas a estes assuntos em realce, como também, surgir insights, ideias para a construção e a criação de novos estudos alicerçados e norteados por temas legitimados e ou consolidados da área de estratégia.

Com isso, acarretou no surgimento de grupos de pesquisas, fortalecimento de redes de colaboração, maturação destas redes, enriquecimento dos estudos com foco na estratégia, condicionando e contribuindo para a intensificação da pesquisa científica da Administração 
no Brasil, à luz dos programas de pós-graduação em Administração e de seus respectivos atores que os fazem existir, ou seja, os estudiosos e suas respectivas instituições nativas.

\section{Conclusões}

O objetivo deste estudo foi investigar o perfil e as características da produção científica divulgada no Evento 3Es durante as Edições de 2003 a 2017, à luz das redes sociais one-mode e two-mode.Para isso, utilizou-se as metodologias das técnicas bibliométricas na primeira fase do estudo; e na segunda fase da pesquisa predominou a análise de redes sociais enfocando as redes one-mode e two-mode para se conseguir assim alcançar e responder satisfatoriamente o objetivo e a questão de pesquisa deste estudo.

Nas redes one-mode verificou-se a presença de redes dispersas e com alta centralidade de grau e de intermediação em ambas as décadas do evento 3Es. Tal fato pode influenciar na não extensão satisfatória das informações trocadas e vislumbradas nas redes dos atores, ou seja, das instituições e dos pesquisadores, pois quanto maior for a conectividade entre estes atores, maior será o conhecimento agregado, evidenciado, socializado e disseminado na área de estratégia (WATANABE; GOMES; HOFFMANN, 2013), contribuindo a posteriori e, consequentemente, no crescimento do campo do saber da estratégia no que afeta ao número de publicações, acadêmicos e IES, em decorrência justamente da maior colaboração na produção científica (ROSSONI et al., 2010).

No tocante a rede de cooperação das instituições nas duas décadas, observou-se que tanto na centralidade de grau como também na centralidade de intermediação as instituições que ficaram em relevo neste estudo foram a USP e a FGV (SP). Este resultado é apoiado nas pesquisas de Bertero, Vasconcelos e Binder (2003),Ribeiro, Muritiba e Muritiba (2012), Ribeiro e Corrêa (2018). É interessante considerar também que, além de serem as mais centrais neste estudo, USP e FGV (SP), são também as mais profícuas em respeito a produção científica de estudos voltados a área de estratégia.

Tal avistamento é confirmado no estudo de Walter et al. (2010) referendando, situando e destacando estas instituições como as mais relevantes no campo da estratégia nacional. É necessário também ponderar que as IESs em destaque nesta pesquisa preservam programas de pós-graduação em Administração maduros, consolidados e legitimados no Brasil.

Relativamente as redes de coautoria, enfatizando as centralidades de grau e de intermediação nas duas décadas de publicação no 3Es, os estudiosos Carlos Ricardo Rossetto, Clóvis L. Machado-da-Silva e Manuel Portugal Ferreira ficaram em realce. Nativos das respectivas IESs: 
UNIVALI, UFPR e UNINOVE (na época em que os estudos divulgados no 3Es foram publicados).

É interessante notar que, apesar de a USP e FGV (SP) serem as instituições mais relevantes e importantes no que tange a produção científica de artigos em estratégia no Brasil, nenhuma destas IESs conceberam pesquisadores entre os mais centrais desta pesquisa, o que nos faz entender e compreender que, apesar da USP e FGV (SP) estarem na berlinda em relação a propagação de estudos sobre estratégia, estas não centralizam suas respectivas publicações em poucos acadêmicos, significando que existem mais pesquisadores atuando nestas duas IESs em destaque na área de estratégia, impactando com isso em seus destaques respectivos nas redes de colaboração.

Este fato também pode ser compreendido e explicado por se tratar de instituições com programas de pós-graduação em Administração já consolidados e legitimados no Brasil, com grupos de pesquisa fortes e atuantes, com mais pesquisadores envolvidos no processo de construção da informação e do conhecimento científico da temática estratégia.

De maneira macro, observa-se a existência de estruturas do tipo small worlds e centro-periferia, nas redes de colaboração das instituições, com impactos proeminentes para a concepção da produção científica em estratégia entre estas instituições em relevo nas Figuras 1.1, 1.2, 2.1 e 2.2, por década de pesquisa. Tal fato é condicionado pela localização geográfica destas IESs, influenciando em seus respectivos realces nos âmbitos local e global das centralidades investigadas. Tais achados são corroborados nos resultados do estudo de Rossoni e Guarido Filho (2007).

Ainda no que confere aos pesquisadores em realce neste estudo, todos estão entre os mais produtivos desta pesquisa. Posto isto, salientase que Carlos Ricardo Rossetto e Manuel Portugal Ferreira tornaram-se destaques na divulgação de estudos em estratégia à luz do 3Es, sobretudo na segunda década do citado evento, influenciando no crescimento de suas respectivas IESs: UNIVALI e UNINOVE na citada década.

Ainda é interessante ressaltar que dos 21 pesquisadores mais profícuos deste trabalho, nove não apareceram entre os mais centrais desta pesquisa. Compreende-se, com isso, que nem sempre publicar muitos estudos, pode impactar e ou contribuir para a centralidade e ou empoderamento deste estudioso em uma rede de coautoria, pois estas publicações podem ser mediante autoria individuais ou em parcerias simples, mitigando a sua respectiva atuação como autor central na rede, que neste caso norteia a área de estratégia.

Também neste estudo aparecem autores centrais que não estão entre os 21 mais prolíferos. E isto é explicado por sua dinamicidade na performance da construção do conhecimento com seus pares, ou seja, mesmo não estando entre os mais produtivos do evento em investigação, 
se conectam com uma gama de outros pesquisadores, contribuindo e influenciando para seu destaque como acadêmicos centrais no campo da estratégia.

No que se refere a rede two-mode que enfatiza em conjunto os autores e os temas identificados deste trabalho, contemplam-se os assuntos que mais chamam a atenção dos pesquisadores para publicação. Sendo assim, as temáticas que mais ficaram em evidência, nas duas décadas investigadas foram: visão baseada em recursos, formulação de estratégia, redes inter e organizacionais, desempenho organizacional, internacionalização, empreendedorismo e inovação.

A visão baseada em recursos tem seu foco no desenvolvimento e na formulação de estratégias diversificadas $e$, consequentemente, na vantagem competitiva (MUNCK; GALLELI, 2015). Constata-se, assim, a importância da formulação de estratégias para a base da vantagem competitiva e para a RBV (SCHNEIDER et al., 2009). Já o tema redes inter e organizacionais destaca-se em razão de sua importância plena na pauta dos estudos organizacionais (BALESTRIN; VERSCHOORE; REYES JUNIOR, 2010) e, simultaneamente, na área de estratégia (MACHADO-DA-SILVA; ROSSONI, 2007).

O relevo do tema desempenho organizacional nos estudos em estratégia é elucidado em decorrência de ser visto como uma iniciativa primordial na gestão empresarial (NASCIMENTO et al., 2011). Outra ação preponderante para se alcançar uma performance empresarial na Administração é a inovação, pois ela é vista como essencial para a perpetuidade e sobrevivência das organizações, em razão da grande competitividade no panorama empresarial (KNEIPP et al., 2011). Posto isto, é viável afirmar que a inovação é um tema emergente no âmbito acadêmico (SCARPIN et al., 2018), confirmando assim seu destaque na produção científica em estratégia no evento científico em investigação.

Antes de adentrar ao próximo tema em realce neste estudo, afirmase que empreender é inovar, observa-se com isso, a inerência do empreendedorismo com a inovação (BORBA; HOELTGEBAUM; SILVEIRA, 2011). Posto isto, contempla-se o tema empreendedorismo como um dos mais publicados neste estudo, e isso pode ser esclarecido em consequência de sua forte conexão com a vantagem competitiva que as organizações buscam. Com isso, o empreendedorismo é visto como tema de pesquisa emergente (OLIVEIRA JUNIOR et al., 2018), reforçando assim seu relevo neste trabalho.

$\mathrm{E}$, por fim, surge o tema internacionalização como o mais divulgado e, consequentemente, como um dos mais centrais nas duas décadas do 3Es. Tal resultado pode ser explicado em razão deste assunto "[...] lestá se tornando cada vez mais importante para a academia brasileira e para a área de Administração em particular" (DINIZ et al., 2019, p. 521), 
provocando discussões na academia, pois sua institucionalização contribui e influencia diretamente na qualidade das publicações dos programas de pós-graduação em Administração no Brasil (GUIMARÃES et al., 2018).

Mas não é apenas no âmbito acadêmico que o tema internacionalização é realçado pelos pesquisadores, mas também no panorama empresarial. $\mathrm{E}$ isso é visto e confirmado mediante as informações retratadas neste estudo, pois, dos 929 artigos identificados nesta pesquisa, 61 enfatizaram diretamente a internacionalização como assunto predominante, sendo que, as pesquisas que enfatizam a internacionalização, enfocaram, de maneira heterogênea, temáticas relacionadas não somente ao foco acadêmico, mas sobretudo no escopo organizacional, embasada e norteada pelo campo do conhecimento, estratégia que impera nas divulgações do evento científico em investigação.

Tal achado, tendo em consideração o destaque da internacionalização no âmbito da estratégia nas publicações em meios de comunicação, é corroborado na pesquisa dos autores Ribeiro e Corrêa (2018), ao contemplarem o citado tema como o mais profícuo na Revista Ibero-Americana de Estratégia a qual acolhe estudos com relevo na área de estratégia no Brasil.

De maneira geral, este estudo traz a tona uma investigação sobre a produção científica da área de estratégia à luz do congresso científico 3Es durante as suas primeiras duas décadas de vida, contribuindo com isso para melhor entender e compreender esta área do saber tão importante para o campo do conhecimento em Administração.

Este estudo, contempla, de maneira contemporânea, indicadores sociométricos mediante as redes de 1 e 2 modos, alargando e robustecendo com isso a difusão e a compreensão da área de estratégia no Brasil, sob a ótica e em estado da arte das redes de colaboração dos pesquisadores e de suas respectivas instituições as quais estes são oriundos, em um panorama ainda não visto na literatura científica nacional, ou seja, em duas décadas e enfatizando as redes de cooperação dos autores e das instituições de ensino. E no que diz respeito as redes de dois modos, usou-se a matriz bipartida ou assimétrica em dois conjuntos de atores, isto é, os autores e os temas por eles pesquisados e divulgados no evento científico ora investigado.

Diante do exposto, o referido estudo evidencia uma quantidade de dados, informações e conhecimentos ainda não visto na academia, pegando por base a análise de redes sociais, e, por meio desta visão pode-se observar como os atores (pesquisas, instituições e temas) se comportaram e seus respectivos perfis de cooperação, criando valor científico e ajudando com isso a melhor entender e compreender a 
importância da área de estratégia, mediante seus atores e temas, sobretudo os mais realçados, na literatura científica nacional.

Resumidamente, pode-se afirmar que a produção científica na área de Administração, com foco no tema da estratégia, à luz do evento científico 3Es, é influenciada pelos padrões estruturais de interação entre os atores (pesquisadores e suas respectivas instituições nativas). Sendo assim, é observado em outras pesquisas similares a esta que padrões de resultados análogos transpõem diferentes temas da área de Administração (RIBEIRO, 2020), indicando que, possivelmente, existem elementos estruturais peculiares aos estudos da área de Administração no Brasil (ROSSONI; GUARIDO FILHO, 2007).

Estes achados contribuem para alargar e robustecer, quem sabe, a referida área na academia, por meio da criação de novos insights, temas, grupos de estudos, pesquisadores, programas de pós-graduação em Administração com enfoque em estratégia, minimizando gargalos de pesquisas, criando pontes de caminhos para uma maior difusão, disseminação e socialização do saber científico em estratégia no Brasil e, quiçá no mundo.

Este estudo limitou-se em investigar a produção científica divulgada no evento científico 3Es em suas primeiras duas décadas de vida à luz das redes sociais de 1 e 2 modos, contudo, tal fato não desmerece a citada pesquisa, visto que ela alcançou e responder o objetivo e a questão de pesquisa respectiva, evidenciando com isso contribuições e conhecimentos contemporâneos, sob uma perspectiva de redes de colaboração não vista antes na literatura acadêmica nacional.

Contudo, é preponderante dar continuidade em pesquisas análogas a essa, replicando-as e gerando mais conhecimento sobre a área de estratégia. Sendo assim, sugere-se para estudos futuros replicar a citada pesquisa mediante uma investigação similar ao que foi realizada aqui, porém, abarcando outros congressos (nacionais e ou internacionais) de envergadura e escopo equivalentes ao que foi investigado, fazendo com isso uma comparação entre eles. Aconselha-se também, quando possível, aperfeiçoar a análise de redes sociais, como, também, vislumbrar mais informações por meio dos indicadores bibliométricos.

\section{Referências}

ALARCÃO, A. L. L.; SACOMANO NETO, M. Actor centrality in network projects and scientific performance: na exploratory study. Revista de Administração e Inovação, v. 13, n. 2, p. 78-88, 2016. DOI:

10.1016/j.rai.2016.03.002.

ANDRADE, L. F. S. ; PAIVA, A. L. de; CASTRO ALCÂNTARA, V. de; BRITO, M. J. Desvelando o campo da estratégia como prática e suas relações. 
Revista Ibero-Americana de Estratégia, v. 15, n. 1, p. 6-26, 2016. DOI: $10.5585 /$ riae.v15i 1.2267.

ARBOIT, A, E.; BUFREM, L. S. Produção de trabalhos científicos em eventos nacionais da área de ciência da informação. Transinformação, v. 23, n. 3, p. 207-217, 2011.

BALESTRIN, A.; VERSCHOORE, J. R.; REYES JUNIOR, E. O campo de estudo sobre redes de cooperação interorganizacional no Brasil. Revista de Administração Contemporânea, v. 14, n. 3, p. 458-477, 2010.

BERTERO, C. O.; CALDAS, M. P.; WOOD JR, T. Produção científica em administração de empresas: provocações, insinuações e contribuições para um debate local. Revista de Administração Contemporânea, v. 3, n. 1, p. 147-178, 1999. DOI: 10.1590/S1415-65551999000100009.

BERTERO, C. O.; VASCONCELOS, F. C. de; BINDER, M. P. Estratégia empresarial: a produção científica brasileira entre 1991 e 2002. Revista de Administração de Empresas, v. 43, n. 4, p. 48-62, 2003.

BIGNETTI, L. P.; PAIVA, E. L. Ora (direis) ouvir estrelas!: estudo das citações de autores de estratégia na produção acadêmica brasileira.

Revista de Administração Contemporânea, v. 6, n. 1, p. 105-125, 2002. DOI: $10.1590 /$ S1415-65552002000100007.

BORBA, M. L. de; HOELTGEBAUM, M.; SILVEIRA, A. A produção científica em empreendedorismo: análise do Academy of Management Meeting: 1954-2005. Revista de Administração Mackenzie, v. 12, n. 2, p. 169-206, 2011. DOI: $10.1590 / S 1678-69712011000200008$.

BUENO, P. V.; ROCHA, D. T. da; SILVA, E. D. da; CRUZ, J. A. W. Estratégia: estudo bibliométrico e sociométrico da produção científica da Revista Brasileira de Estratégia (REBRAE) 2008-2012. Ciências Sociais Aplicadas em Revista, v. 14, n. 27, p. 84-104, 2014.

CAMARGOS, M. A. de; DIAS, A. T. Estratégia, administração estratégica e estratégia corporativa: uma síntese teórica. Revista de Gestão da USP, v. 10, n. 1, p. 27-39, 2003.

CASSUNDÉ, F. R. de S. A.; BARBOSA, M. A. C.; MENDONÇA, J. R. C. Entre revisões sistemáticas e bibliometrias: como tem sido mapeada a produção acadêmica em administração no Brasil? Informação \& Informação, v. 23, n. 1, p. 311-334, 2018. DOI: 10.5433/1981-8920.2018v23n1p311.

COORDENAÇÃO DE APERFEIÇOAMENTO DE PESSOAL DE NÍVEL SUPERIOR - CAPES. Ciências Sociais Aplicadas. Disponível em: https://www.gov.br/capes/pt-br/acesso-a-informacao/acoes-e- 
programas/avaliacao/sobre-a-avaliacao/areas-avaliacao/sobre-as-areasde-avaliacao/colegio-de-humanidades/ciencias-sociais-aplicadas. Acesso em: 27 out. 2021.

CRUZ, A. P. C. D.; ESPEJO, M. M. D. S. B.; COSTA, F.; ALMEIDA, L. B. D. Perfil das redes de cooperação científica: congresso USP de controladoria e contabilidade-2001 a 2009. Revista Contabilidade \& Finanças, v. 22, n. 55, p. 64-87, 2011. DOI: 10.1590/S1519-70772011000100005.

CUNHA, J. A. C. da; DEFINA, D. A.; PASSADOR, J. L. Qualidade da produção científica no Brasil: um enfoque nos trabalhos premiados pelos congressos da Anpad 2004-2012. Revista de Ciências da Administração, v. 16 , n. 38, p. 11-28, 2014. DOI: 10.5007/2175-8077.2014v16n38p 11.

DINIZ, E. H.; OLIVEIRA, H. P. G. D.; FAVARETTO, J. E. R.; BRÓLIO, D. R. Incentivos para Internacionalização são Adequados? Percepção dos Pesquisadores em Administração da Informação. Revista de Administração Contemporânea, v. 23, n. 4, p. 520-542, 2019. DOI: 10.1590/19827849rac2019180232.

ENCONTRO DA ASSOCIAÇÃO NACIONAL DE PÓS-GRADUAÇÃO E PESQUISA EM ADMINISTRAÇÃO. Apresentação. Disponível em: http://www.anpad.org.br/. Acesso em: 27 out; 2021.

FAVARETTO, J. E. R.; FRANCISCO, E. R. de. Exploração do acervo da RAERevista de Administração de Empresas (1961 a 2016) à luz da bibliometria, text mining, rede social e geoanálise. Revista de Administração de Empresas, v. 57, n. 4, p. 365-390, 2017. DOI: $10.1590 /$ S0034-759020170407.

FERREIRA ARAÚJO, R.; ALVARENGA, L. A bibliometria na pesquisa científica da pós-graduação brasileira de 1987 a 2007. Encontros Bibli: Revista Eletrônica de Biblioteconomia e Ciência da Informação, v. 16, n. 31, p. 51-70, 2011. DOI: 10.5007/1518-2924.2011v16n31p51.

FERREIRA, V. da R. S.; NAJBERG, E.; PORTO, R. B.; SOUSA, M. de M.; BARBOSA, N. B. Pesquisa sobre estratégia no setor público brasileiro: avaliação da produção científica no período 2007 - 2011. Revista Contemporânea de Economia e Gestão, v. 13, n. 1, p. 85-104, 2015.

FRANCISCO, E. D. R. RAE-eletrônica: exploração do acervo à luz da bibliometria, geoanálise e redes sociais. Revista de Administração de Empresas, v. 51, n. 3, p. 280-306, 2011.

GALLON, A. V.; SOUZA, F. C. de; ROVER, S.; VAN BELLEN, H. M. Um estudo longitudinal da produção científica em administração direcionada à temática ambiental. Revista Alcance, v. 15, n. 1, p. 81-101, 2008. 
GONÇALES FILHO, M.; CAMPOS, F. C. de; ASSUMPÇÃO, M. R. P. Revisão sistemática da literatura com análise bibliométrica sobre estratégia e Manufatura Enxuta em segmentos da indústria. Gestão \& Produção, v. 23, n. 2, p. 408-418, 2016. DOI: 10.1590/0104-530X1683-14.

GUARIDO FILHO, E. R.; MACHADO-DA-SILVA, C. L. O desenvolvimento da teoria institucional no campo de estudos organizacionais no Brasil. Cadernos EBAPE.BR, v. 8, n. 2, p. 278-301, 2010.

GUIMARÃES, T. A. ; MOTTA, G. D. S.; FARIAS, S. A. D.; KIMURA, H.; QUINTELLA, R. H.; CARNEIRO, J. M. T. A ANPAD e o processo de institucionalização da comunidade científica brasileira de Administração. Cadernos EBAPE. BR, v. 16, n. Edição Especial, p. 523-537, 2018. DOI: 10.1590/1679-395173273.

GUIMARÃES, T. D. A.; GOMES, A. D. O.; ODELIUS, C. C. ; ZANCAN, C. ; CORRADI, A. A. A rede de programas de pós-graduação em administração no Brasil: análise de relações acadêmicas e atributos de programas. Revista de Administração Contemporânea, v. 13, n. 4, p. 564-582, 2009.

KNEIPP, J. M.; ROSA, L. A. B. da; BICHUETI, R. S.; PERLIN, A. P.; SCHUCH JÚNIOR, V. F. Uma análise da evolução da produção científica sobre inovação no Brasil. Revista Eletrônica de Estratégia \& Negócios, v. 4, n. 1, p. 133-157, 2011.

LEITE FILHO, G. A. Perfil da produção científica dos docentes e programas de pós-graduação em ciências contábeis no Brasil. Revista de Contabilidade e Controladoria, v. 2, n. 2, p. 1-13, 2010.

MACADAR, M. A.; GRAEML, A. R. Refletindo sobre a área de ADI: O que pensam os pesquisadores da área? Revista Eletrônica de Administração, v. 16 , n. 2, p. 348-372, 2010.

MACHADO-DA-SILVA, C. L.; ROSSONI, L. Persistência e mudança de temas na estruturação do campo científico da estratégia em organizações no Brasil. Revista de Administração Contemporânea, v. 11, n. 4, p. 33-58, 2007. DOI: $10.1590 /$ S1415-65552007000400003.

MACHADO JUNIOR, C.; SOUZA, M. T. S. de; BAZANINI, R.; SILVA, H. H. M. da. Rede social formada pelos pesquisadores em sustentabilidade ambiental. Revista Científica Hermes, n. 16, 90-114, 2016.

MARCON, R.; BANDEIRA-DE-MELLO, R. Estratégia em organizações: a produção científica brasileira entre 2003 e 2011. Revista Alcance, v. 23, n. 2, p. 127-141, 2016. DOI: alcance.v23n2.p127-141. 
MATHEUS, R. F.; SILVA, A. B. D. O. Análise de redes sociais como método para a Ciência da Informação. DataGramaZero-Revista de Ciencia da informação, v. 7, n. 2, p. 2006.

MATOS, O. A. ; VENÂNCIO, D. M.; DUTRA, A. Gestão estratégica em instituições de ensino superior: mapeamento das publicações científicas no período de 1997 a 2012. Revista Gestão Universitária na América Latina, v. 7, n. 1, p. 106-127, 2014. DOI: 10.5007/19834535.2014v7n1p106.

MEDEIROS ARAÚJO, R.; AZEVEDO, A. K. de; VIEIRA, L. L.; NASCIMENTO, T. C. Periódicos em ação: um estudo exploratório-bibliométrico na área de Administração, Ciências Contábeis e Turismo. Perspectivas em Ciência da Informação, v. 19, n. 1, p. 90-114, 2014. DOI: 10.1590/S141399362014000100007.

MENDES-DA-SILVA, W.; ONUSIC, L. M.; GIGLIO, E. M. Rede de pesquisadores de finanças no Brasil: um mundo pequeno feito por poucos. Revista de Administração Contemporânea, v. 17, n. 6, p. 739-763, 2013.

MIRANDA, R. C. da R. Conhecimento estratégico: caracterização e identificação baseada em revisão sistemática e bibliométrica. Informação \& Sociedade: Estudos, v. 28, n. 1, p. 23-34, 2018.

MORAES, M.; FURTADO, R. L.; TOMAÉL, M. I. Redes de Citação: estudo de rede de pesquisadores a partir da competência em informação. Em Questão, v. 21, n. 2, p. 181-202, 2015. DOI: 10.19132/18085245212.181-202.

MUNCK, L.; GALLELI, B. Avanços e desafios da conceituação e operacionalização das competências organizacionais em 15 anos de produção científica internacional. Revista de Gestão, v. 22, n. 4, p. 525544, 2015. DOI: 10.5700/576.

NASCIMENTO, S. do; BEUREN, I. M. Redes sociais na produção científica dos programas de pós-graduação de ciências contábeis do Brasil. Revista de Administração Contemporânea, v. 15, n. 1, p. 47-66, 2011. DOI: 10.1590/S1415-65552011000100004.

NASCIMENTO, S. de; BORTOLUZZI, S. C.; DUTRA, A.; ENSSLIN, S. R. Mapeamento dos indicadores de desempenho organizacional em pesquisas da área de Administração, Ciências Contábeis e Turismo no período de 2000 a 2008. Revista de Administração da USP, v. 46, n. 4, p. 373-391, 2011. DOI: $10.5700 /$ rausp1018.

OLIVEIRA JUNIOR, A. B. D.; GATTAZ, C. C.; BERNARDES, R. C.; IIZUKA, E. S. Pesquisa em empreendedorismo (2000-2014) nas seis principais 
revistas brasileiras de administração: lacunas e direcionamentos. Cadernos EBAPE. BR, v. 16, n. 4, p. 610-630, 2018. DOI: 10.1590/1679395167644.

PARREIRAS, F. S. ; SILVA, A. B. D. O.; MATHEUS, R. F.; BRANDÃO, W. C. REDECI: colaboração e produção científica em ciência da informação no Brasil. Perspectivas em Ciência da Informação, v. 11, n. 3, p. 302-317, 2006.

PAULI, J.; BASSO, K.; GOBI, R. L. ; BILHAR, A. O Efeito da Densidade da Rede de Coautoria no Desempenho dos Programas de Pós-graduação. Brazilian Business Review, v. 16, n. 6, p. 576-588, 2019. DOI: 10.15728/bbr.2019.16.6.3.

RIBEIRO, H. C. M. Analisando a colaboração e produção científica da área ensino e pesquisa em Administração e Contabilidade. Perspectivas em Ciência da Informação, v. 25, n. 2, p. 194-222, 2020. DOI: $10.1590 / 1981-5344 / 3915$.

RIBEIRO, H. C. M. Controladoria e contabilidade gerencial: dez anos de produção científica. Pretexto, v. 20, n. 2, p. 100-121, 2019. DOI: 10.21714/pretexto.v20i2.6043.

RIBEIRO, H. C. M.; CORRÊA, R. Estado da arte da Revista de Administração Mackenzie: análise da produção científica de 2008 a 2012. Revista Gestão Universitária na América Latina, v. 7, n. 2, p. 152-174, 2014. DOI: 10.5007/1983-4535.2014v7n2p152.

RIBEIRO, H. C. M. ; CORRÊA, R. Redes sociais: um estudo em uma instituição de ensino superior privado. Revista Metropolitana de Sustentabilidade, v. 3, n. 2, p. 110-128, 2013.

RIBEIRO, H. C. M.; CORRÊA, R. Revista Ibero-Americana de Estratégia: produção acadêmica de 2002 a 2015. Perspectivas em Gestão \& Conhecimento, v. 8, n. 1, p. 210-231, 2018. DOI: 10.21714/2236417X2018v8n1p210.

RIBEIRO, H. C. M.; CORRÊA, R.; RIBEIRO, G. K. M. Redes sociais de um e dois modos: trajetória da produção científica do Encontro de Ensino e Pesquisa em Administração e Contabilidade. Revista Gestão Universitária na América Latina, v. 12, n. 2, p. 253-270, 2019. DOI: 10.5007/19834535.2019v12n2p 253.

RIBEIRO, H. C. M.; COSTA, B. K.; FERREIRA, M. A. S. P. V. Produção acadêmica dos temas estratégia e governança corporativa. Revista de Administração FACES, v. 13, n. 3, p. 28-46, 2014. 
RIBEIRO, H. C. M. Doze anos de estudo da Revista de Administração Pública à luz da bibliometria e da rede social. Revista Ciências Administrativas, v. 20, n. 1, p. 137-167, 2015.

RIBEIRO, H. C. M.; MURITIBA, S. N.; MURITIBA, P. M. Perfil e crescimento dos temas "governança corporativa" e "estratégia": uma análise dos últimos 11 anos nos periódicos da área de administração no Brasil. Gestão \& Regionalidade, v. 28, n. 82, p. 83-99, 2012.

RIBEIRO, H. C. M.; RIBEIRO, G. K. M. Análise de dez anos da produção acadêmica divulgada nos estudos científicos publicados no congresso ANPCONT. Revista Ciências Administrativas, v. 25, n. 1, p. 1-18, 2019. DOI: $10.5020 / 2318-0722.2019 .7945$.

RIBEIRO, H. C. M.; SANTOS, M. C. dos. Artigos bibliometricos: produção acadêmica divulgada nos periódicos nacionais sob a ótica da análise de rede social. Revista Gestão Universitária na América Latina, v. 10, n. 2, p. 229-248, 2017. DOI: 10.5007/1983-4535.2017v10n2p229.

ROCHA, D. T.; WALTER, S. A.; SILVA, E. D. D.; GIMENEZ, F. A. P. Processo de formação de estratégia em pequenas empresas: um estudo bibliométrico e sociométrico. Revista da Micro e Pequena Empresa, v. 5, n. 1, p. 102-119, 2011.

ROSSONI, L.; GUARIDO FILHO, E. R. Cooperação interinstitucional no campo da pesquisa em estratégia. Revista de Administração de Empresas, v. 47, n. 4 , p. 74-88, 2007.

ROSSONI, L.; GUARIDO FILHO, E. R.; FRANCISCONI, K.; ALBUQUERQUE FILHO, J. B. Cooperação, estratificação e perfil da pesquisa em estratégia no Brasil. Revista Eletrônica de Ciência Administrativa, v. 9, n. 2, p. 181197, 2010. DOI: 10.5329/RECADM.20100902005.

ROSSONI, L.; GUARIDO FILHO, E. R. Onipresença nos conselhos editoriais: prestígio e cerimonialismo na atividade científica. Redes. Revista Hispana para el Análisis de Redes Sociales, v. 22, n. 8, p. 190218, 2012.

ROSSONI, L.; HOCAYEN-DA-SILVA, A. J.; FERREIRA JÚNIOR, I. (2008). Estrutura de relacionamento entre instituições de pesquisa do campo de ciência e tecnologia no Brasil. Revista de Administração de Empresas, v. 48, n. 4, p. 34-48, 2012.

SARAIVA, E. V.; CARRIERI, A. de P. Citações e não citações na produção acadêmica de estratégia no Brasil: uma reflexão crítica. Revista de Administração da USP, v. 44, n. 2, p. 158-166, 2009. 
SCARPIN, M. R. S.; MACHADO, D. D. P. N.; MONDINI, V. E. D.; GOMES, G. Produção científica de inovação no Brasil: uma análise sob a ótica das redes sociais. Revista de Administração da UFSM, v. 11, n. 6, p. 19-39, 2018. DOI: 10.5902/19834659 14464.

SCHNEIDER, A. B.; CARNEIRO, M. L.; SERRA, F. A. R.; FERREIRA, M. P. Estratégia competitiva: Michael Porter 30 anos depois. Revista de Administração da UFSM, v. 2, n. 2, p. 298-326, 2009.

SOARES, M. de N. M.; LESSA, B. S.; CABRAL, A. C. A.; PESSOA, M. N. M.; SANTOS, S. M. A participação feminina nos estudos sobre estratégia. Revista RAUnP, v. 7, n. 1, p. 25-37, 2015.

VILELA, N. G. S.; LOURENÇO, M. L.; RESE, N. Cultura organizacional no brasil: um estudo sistemático da relação entre grupos de pesquisa e produção científica nos principais periódicos e eventos em administração nos anos de 2006 a 2015. Revista de Ciências da Administração, v. 19, n. 48, p. 122-135, 2017.

TESTON, S. de F.; FILIPPIM, E. S. O modelo tridimensional e o processo de sucessão. Revista de Governança Corporativa, v. 5, n. 2, p. 23-47, 2019.

TOMAÉL, M. I.; MARTELETO, R. M. Redes sociais de dois modos: aspectos conceituais. Transinformação, v. 25, n. 3, p. 245-253, 2013.

WALTER, S. A.; BACH, T. M.; BARBOSA, F. Estratégia como prática: análise longitudinal por meio de bibliometria e sociometria. Revista Brasileira de Estratégia, v. 5, n. 3, p. 307-323, 2012. DOI: 10.7213/rebrae.6073.

WALTER, S. A.; LANZA, B. B. B.; SATO, K. H.; SILVA, E. D. da; BACH, T. M. Análise da produção científica de 1997 a 2009 na área de estratégia: produção e continuidade de atores e cooperação entre instituições brasileiras e estrangeiras. Anais eletrônicos [...], XXXIV EnANPAD. Rio de Janeiro / RJ, 2010.

WALTER, S. A.; BACH, T. M.; LANZA, B. B. B.; SATO, K. H. Publicação científica na área de estratégia do Enanpad e do 3es: de 1997 a 2010. Revista Ibero-Americana de Estratégia, v. 12, n. 2, p. 69-104, 2013.

WASSERMAN, S.; FAUST, K. Social network analysis: methods and applications. Cambridge (MA): Cambridge University Press, 1994.

WATANABE, E. A.; GOMES, A. O.; HOFFMANN, V. E. Cooperação entre grupos de pesquisa em estratégia no Brasil. Revista Ibero-Americana de Estratégia, v. 12, n. 1, p. 84-106, 2013. 